\title{
Are DBA/2 mice associated with schizophrenia-like endophenotypes? A behavioural contrast with C57BL/6 mice
}

\author{
Journal Article \\ Author(s): \\ Singer, Philipp; Feldon, Joram; Yee, Benjamin K. \\ Publication date: \\ 2009 \\ Permanent link: \\ https://doi.org/10.3929/ethz-b-000018979 \\ Rights / license: \\ $\underline{\text { In Copyright - Non-Commercial Use Permitted }}$ \\ Originally published in: \\ Psychopharmacology 206(4), https://doi.org/10.1007/s00213-009-1568-6
}




\title{
Are DBA/2 mice associated with schizophrenia-like endophenotypes? A behavioural contrast with $\mathrm{C} 57 \mathrm{BL} / 6$ mice
}

\author{
Philipp Singer • Joram Feldon • Benjamin K. Yee
}

Received: 18 November 2008 / Accepted: 7 May 2009/Published online: 30 May 2009

(C) Springer-Verlag 2009

\begin{abstract}
Rationale Due to its intrinsic deficiency in prepulse inhibition (PPI), the inbred DBA/2 mouse strain has been considered as an animal model for evaluating antipsychotic drugs. However, the PPI impairment observed in DBA/2 mice relative to the common $\mathrm{C} 57 \mathrm{BL} / 6$ strain is confounded by a concomitant reduction in baseline startle reactivity. In this study, we examined the robustness of the PPI deficit when this confound is fully taken into account.

Materials and methods Male DBA/2 and C57BL/6 mice were compared in a PPI experiment using multiple pulse stimulus intensities, allowing the possible matching of startle reactivity prior to examination of PPI. The known PPI-enhancing effect of the antipsychotic, clozapine, was then evaluated in half of the animals, whilst the other half was subjected to two additional schizophrenia-relevant behavioural tests: latent inhibition (LI) and locomotor reaction to the psychostimulants-amphetamine and phencyclidine.

Results PPI deficiency in DBA/2 relative to $\mathrm{C} 57 \mathrm{BL} / 6$ mice was essentially independent of the strain difference in baseline startle reactivity. Yet, there was no evidence that $\mathrm{DBA} / 2$ mice were superior in detecting the PPI-facilitating effect of clozapine when startle difference was balanced. Compared with C57BL/6 mice, DBA/2 mice also showed impaired LI and a different temporal profile in their responses to amphetamine and phencyclidine.

Conclusion Relative to the C57BL/6 strain, DBA/2 mice displayed multiple behavioural traits relevant to schizophrenia
\end{abstract}

P. Singer $\cdot$ J. Feldon $\cdot$ B. K. Yee $(\bowtie)$

Laboratory of Behavioural Neurobiology,

Federal Institute of Technology Zurich,

Schorenstrasse 16,

8603 Schwerzenbach, Switzerland

e-mail: byee@ethz.ch psycho- and physiopathology, indicative of both dopaminergic and glutamatergic/ $N$-methyl-D-aspartic acid receptor dysfunctions. Further examination of their underlying neurobiological differences is therefore warranted in order to enhance the power of this specific inter-strain comparison as a model of schizophrenia.

Keywords Amphetamine - Behavioural genetic . Latent inhibition · Mouse · Phencyclidine .

Prepulse inhibition $\cdot$ Schizophrenia

\section{Introduction}

Behavioural phenotypic divergence between strains of laboratory rodents is relevant to behavioural genetics and provides an opportunity to develop animal models of specific psychopathological traits. One approach is to develop selective breeding (e.g. Logue et al. 1997; McCaughran et al. 1997; Schwabe et al. 2007), whilst another is to compare existing, usually inbred strains with relatively stable genetic backgrounds (Bullock et al. 1997; Crawley et al. 1997; Paylor and Crawley 1997). The inbred DBA/2 mouse strain has attracted interests recently in its potential relevance to psychosis-related traits in comparison to another common inbred mouse strain-the C57BL/6 strain - as the reference line (Olivier et al. 2001; Spielewoy and Markou 2004). DBA is the oldest recorded inbred mouse strain originating from Little in 1909, and substrains DBA/1 and DBA/2 were established in 1929-1930, both of which are now maintained in the Jackson Laboratory (see Mouse Genome Informatics at http://www.informatics.jax. org/external/festing/mouse/docs/DBA.shtml). Since the 1960s, strain comparison studies have reported various notable behavioural phenotypes in the $\mathrm{DBA} / 2$ substrain, 
as catalogued in the Mouse Genome Informatics database (see link above). A number of cognitive traits revealed in DBA/2 mice, such as spatial memory deficits, have led to the suggestion that they may represent a model of hippocampal dysfunction (Ammassari-Teule et al. 1995; Paylor et al. 1993).

Of particular relevance to psychotic traits is the consistent reporting of weak prepulse inhibition (PPI) expression and related physiological gating in $\mathrm{DBA} / 2$ mice (e.g. Bortolato et al. 2007; Bullock et al. 1997; Logue et al. 1997; McCaughran et al. 1997; Olivier et al. 2001; Stevens et al. 1996; Stevens and Wear 1997). PPI represents a form of sensorimotor gating that is deficient in schizophrenia patients, and it can be readily demonstrated in humans as well as in animals using the ubiquitous acoustic startle reflex (Hoffman and Searle 1965). PPI is commonly demonstrated by the reduction in the startle reaction to a loud pulse stimulus when it is shortly preceded by a brief, non-startling prepulse stimulus. It is therefore a powerful translational paradigm for dysfunction in pre-attentive information processing and sensorimotor gating which exists in various psychiatric disorders, including schizophrenia (Braff et al. 2001; Csomor et al. 2009; Geyer et al. 2002; Swerdlow and Geyer 1998; Swerdlow et al. 2008). A number of comparative studies between inbred mouse strains have revealed considerable divergence in PPI expression (e.g. Bullock et al. 1997; Geyer et al. 2002; Logue et al. 1997; McCaughran et al. 1997; Paylor and Crawley 1997) and led to the suggestion that mouse strains with low basal levels of PPI may be useful in studying the neural basis of PPI deficiency without the requirement of additional pharmacological interventions to induce a PPI deficit (see McCaughran et al. 1997). Olivier et al. (2001) further proposed more specifically that the weak PPI phenotype observed in the DBA/2 substrain (relative to other mouse strains) may serve as a model to screen for antipsychotic drugs - a recommendation that has been adopted in a number of recent psychopharmacological studies of novel antipsychotics, including histamine H3 receptor antagonists (Browman et al. 2004; Fox et al. 2005) and glycine transporter 1 inhibitors (Boulay et al. 2008; Depoortère et al. 2005; Kinney et al. 2003).

However, past studies have largely overlooked the concomitant change in startle reaction magnitude. In DBA $/ 2$ mice, the reported PPI deficits are confounded by a pronounced reduction in startle reaction (e.g. Bortolato et al. 2007; Crawley et al. 1997; McCaughran et al. 1997; Paylor and Crawley 1997). This is of significant concern because differences in the baseline startle reactivity can seriously complicate or confound the interpretation of the results obtained on PPI (Csomor et al. 2006, 2008; Hoffman and Searle 1965; Swerdlow et al. 2000; Yee et al. 2005). The dependency of PPI magnitude on baseline startle reactivity has been demonstrated in rodents and humans (Csomor et al. 2006, 2008; Hince and MartinIverson 2005; Yee et al. 2005) - a finding that has been incorporated also by computational models of PPI (Sandner and Canal 2007; Schmajuk and Larrauri 2005). The present study was undertaken to initially address the confounding phenotype on startle reactivity in comparison with C57BL/6 mice using a more stringent parametric design of PPI assessment incorporating multiple pulse intensities (Csomor et al. 2006, 2008; Yee et al. 2005). With this PPI design, we went on to investigate if the DBA/2 substrain may enjoy superior sensitivity (compared with $\mathrm{C} 57 \mathrm{BL} / 6$ mice) in the detection of atypical neuroleptic drugs using clozapine as the reference compound.

The present study also includes comparisons between DBA/2 and C57BL/6 mice in another behavioural paradigm of psychosis-related attentional deficits, namely latent inhibition (LI). Unlike PPI, LI refers to a form of learned attentional control by which repeated exposures to an inconsequential stimulus lead to a loss of associability of the stimulus, as shown by its weakened ability to enter into association with other significant stimuli in Pavlovian and instrumental conditioning paradigms (Lubow and Moore 1959). LI is also deficient in some subsets of schizophrenia patients (e.g. Baruch et al. 1988; Gray et al. 1992; Williams et al. 1998), and it has been suggested that a distinction between pathological traits associated with positive and negative symptoms of schizophrenia can be achieved by appropriate parametric variation of the LI paradigm (see Weiner 2003). Such manipulation was included here, thus allowing an important extension to previous studies of LI expression in DBA/2 mice (Baarendse et al. 2008; Gould and Wehner 1999; Restivo et al. 2002). Finally, we also evaluated in the comparison between DBA/2 and C57BL/6 mice whether the former would exhibit pharmacologically induced phenotypes that are in keeping with the dopamine and glutamate $/ N$-methyl-D-aspartic acid (NMDA) hypotheses of schizophrenia (c.f. Coyle 2006; Carlsson 1988; Javitt 2007; Snyder 1976). To this end, the animals were subjected to acute challenge either of an indirect dopamine receptor agonist, amphetamine, or the non-competitive NMDA receptor antagonist, phencyclidine (PCP).

\section{Materials and methods}

\section{Subjects}

Adult male C57BL/6 $(n=36)$ and DBA/2 $(n=40)$ mice were obtained from the Charles River Laboratories (Germany). They were kept in groups of four to five in Makrolon ${ }^{\circledR}$ type III cages (Techniplast, Milan, Italy) and housed in an animal vivarium under a reversed 12/12-h light-dark cycle 
(lights on 2000-0800 hours) with ad lib food and water throughout the entire experimental period. The mice were acclimatised to the laboratory housing conditions for 2 weeks before the commencement of behavioural testing at an age of approximately 12 weeks. The tests were all conducted in the dark phase of the light-dark cycle. All procedures performed on the animals had been approved by the Zurich Cantonal Veterinary Office, in accordance with the Animal Protection Act of Switzerland (1978), the European Council Directives 86/609/EEC on animal experimentation and the Principles of Laboratory Animal Care (NIH publication no. 86-23, revised 1985).

\section{Overall experimental design}

First of all, in experiment 1, PPI was evaluated in all the animals, after which they were subdivided into two balanced cohorts in terms of mean startle reactivity and PPI expression. One cohort then was subjected to another PPI experiment in which the efficacy of clozapine to modify PPI expression was examined with a $2 \times 2$ (strain $\times$ drug) factorial design (experiment $2 ; n=9$ or 10 per cell). From the second cohort, $16 \mathrm{DBA} / 2$ mice and $16 \mathrm{C} 57 \mathrm{BL} / 6$ mice were randomly selected and further subdivided for two separate LI experiments, each using a different number of stimulus pre-exposures (experiments $3 \mathrm{~A}$ and $3 \mathrm{~B} ; n=4$ per cell). Due to time limitations (for the experiments to be completed in 2 days) and the availability of just four shuttle boxes, experiments $3 \mathrm{~A}$ and $3 \mathrm{~B}$ together were carried out with only 32 out of the available 38 animals. Following the completion of experiment 3 , the animals were evaluated in locomotor reaction to amphetamine or PCP in comparison with saline vehicle treatment (experiment $4 ; n=5$ or 6 per cell). The overall experimental plan including sequence, duration of each test, number of rest days between tests and the number of subjects are summarised in Fig. 1.

Prepulse inhibition of the acoustic startle reflex

Apparatus The apparatus consisted of four acoustic startle chambers for mice (SR-LAB, San Diego Instruments, San Diego, CA, USA) each containing a non-restrictive clear Plexiglas cylindrical enclosure attached to a horizontal mobile platform, which, in turn, rested on a solid base inside a sound-attenuated isolation cubicle. A highfrequency loudspeaker, mounted directly above the animal enclosure inside each cubicle, produced a continuous background noise of $65 \mathrm{~dB}_{\mathrm{A}}$, together with the various acoustic stimuli in the form of white noise. The forces acting on the Plexiglas enclosure caused by the whole-body startle response of the animal were converted into analogue signals by a piezoelectric unit attached to the platform. These signals were digitised and stored by a computer. A total of 130 readings were taken at 0.5 -ms intervals (i.e. spanning $65 \mathrm{~ms}$ ), starting at the onset of the startle stimulus in pulse-alone and prepulse-plus-pulse trials and at the onset of the prepulse stimulus in prepulse-alone trials. The average amplitude over the $65 \mathrm{~ms}$ was used to determine the stimulus reactivity. The sensitivity of the stabilimeter was routinely calibrated to ensure consistency between chambers and across sessions.

Procedures Here, we adopted the procedures and testing parameters developed by Yee et al. (2005). PPI was assessed in a test session lasting for approximately $40 \mathrm{~min}$ in which the subjects were presented with a series of discrete trials comprising a mixture of four types of trial. These included pulse-alone trials, prepulse-plus-pulse trials, prepulse-alone trials and trials in which no discrete stimulus, other than the constant background noise, was presented ("no-stimulus" trials). A reduction of startle magnitude in prepulse-plus-pulse trials relative to that in pulse-alone trials (of the same pulse intensity) constitutes PPI. Pulse stimuli of 40-ms duration and of three different intensities were employed: 100,110 and $120 \mathrm{~dB}_{\mathrm{A}}$. Prepulse stimuli of 20-ms duration were employed with three different intensities: 71,77 and $83 \mathrm{~dB}_{\mathrm{A}}$ (corresponding to 6, 12 and 18 decibel units above background, respectively). In the prepulse-plus-pulse trials, a stimulus onset asynchrony of $100 \mathrm{~ms}$ was used.

A session began when the animals were placed into the Plexiglas enclosure. They were acclimatised to the apparatus for 2 min and then presented with three blocks of trials. The first block comprised six pulse-alone trials: two trials of each of the three possible pulse intensities. These trials served to habituate and stabilise the animals' startle response and were analysed separately. In the intermediate block, the animals were presented with ten series of discrete test trials. Each series consisted of the following trials: three pulse-alone trials $\left(100,110\right.$ or $\left.120 \mathrm{~dB}_{\mathrm{A}}\right)$, three prepulsealone trials $(+6,+12$ or +18 decibel units above background) and nine possible combinations of prepulse-plus-pulse trials (three levels of prepulse $\times$ three levels of pulse) and one nostimulus (or background alone) trial. The 16 discrete trials within each series were presented in a pseudorandom order, with a variable inter-trial interval of a mean of $15 \mathrm{~s}$ (ranging from 10 to $20 \mathrm{~s}$ ). The session was concluded with a final block of six consecutive pulse-alone trials as in the first block.

Drug administration In experiment 2 (see Fig. 1), the animals were administered with either clozapine or vehicle solution 45 min prior to PPI testing. Allocation of subjects to drug conditions was counterbalanced with respect to baseline PPI and startle reactivity scores obtained in experiment 1. Thus, the repeated use of animals from 


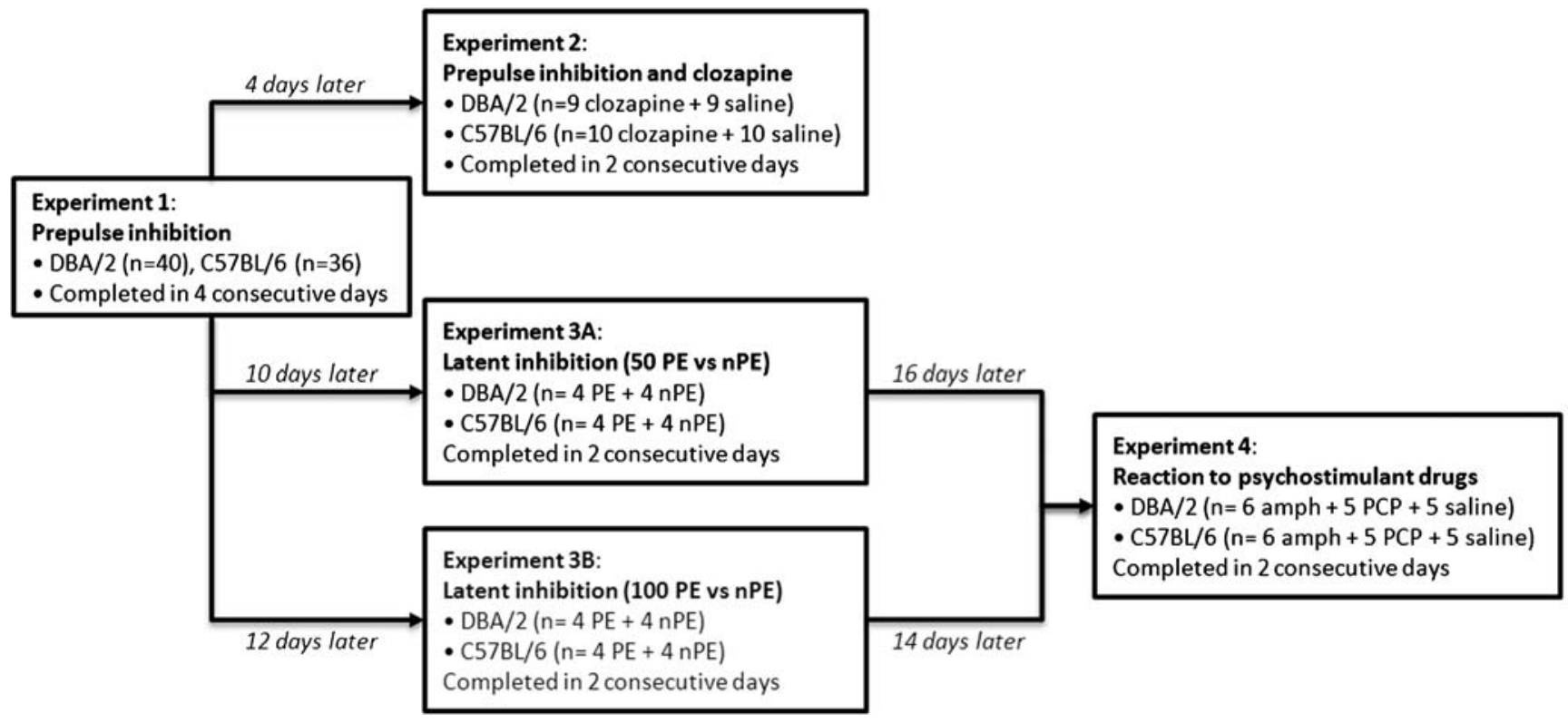

Fig. 1 Summary of the overall experimental design in the present study. $P E$ pre-exposure condition, $n P E$ non-pre-exposure condition, amph amphetamine, $P C P$ phencyclidine. Days of rest between experiments indicated just above or below the arrows

experiments 1 to 2 offered a distinct advantage. The replication of the baseline difference in PPI expression between strains in experiment 2 (see later) confirmed that the results obtained in experiment 2 were unlikely to be biased by the repeated use of the same animals as such. Clozapine (obtained from Sigma-Aldrich, Germany) was dissolved in $0.1 \mathrm{~N} \mathrm{HCl}$ in physiological saline solution and then neutralised to pH5.5 with $\mathrm{Na}_{2} \mathrm{CO}_{3}$ to achieve the desired dose of $1 \mathrm{mg} / \mathrm{kg}$. For the vehicle treatment, physiological saline/lactic acid (pH5.5) was prepared. All substances were freshly prepared on the day of injection and administered in a volume of $5 \mathrm{ml} / \mathrm{kg}$ body weight via the intraperitoneal route (i.p.).

Latent inhibition in two-way active avoidance learning

Apparatus The apparatus comprised four identical two-way shuttle boxes (model H10-11M-SC; Coulbourn Instruments) each housed within a sound-attenuating chest, as described fully elsewhere (Chang et al. 2007; Yee et al. 2006). With internal dimensions of $35.5 \times 17 \times 21.5 \mathrm{~cm}$, each box was divided into two identical compartments by an aluminium wall with an interconnecting opening $(6.77 \times$ $7.7 \mathrm{~cm}$ ), allowing free movement of the animal from one compartment to the other (i.e. a shuttle response). The grid floor was made of stainless steel rods (diameter, $0.4 \mathrm{~cm}$; spaced at $0.7 \mathrm{~cm}$ centre-to-centre) through which electric shocks $(0.3 \mathrm{~mA})$ generated by a shock module (model H101M-XX-SF; Coulbourn Instruments) could be delivered. The conditioned stimulus (CS) was an $85 \mathrm{~dB}_{\mathrm{A}}$ white noise generated by a tone module (model E12-02; Coulbourn
Instruments) mounted behind the shuttle box. Shuttle response was detected by a series of photocells (H2095X; Coulbourn Instruments) mounted on the sides of both compartments. The boxes were illuminated during the entire experimental session by two diffused light sources $(1.1 \mathrm{~W})$, one mounted on the end wall of each compartment $19 \mathrm{~cm}$ above the grid floor. Background noise was provided by a ventilation fan mounted at the back of each shuttle box.

Procedures Weiner (2003) emphasises that abnormality in LI may assume the form of an attenuation (against the presence of strong LI in controls) or abnormal persistence (against the absence of LI in controls). It would be necessary to examine both these possibilities. Here, we manipulated the magnitude of $\mathrm{LI}$ in the $\mathrm{C} 57 \mathrm{BL} / 6$ group by varying the number of stimulus pre-exposures. With 100 stimulus pre-exposures, robust LI was obtained in C57BL/6 mice, whilst 50 pre-exposures yielded no significant LI in this strain of mice in two-way active avoidance (P. Singer, W-N. Zhang, J. Feldon and B.K. Yee, unpublished data). Otherwise, the procedures for the two experiments were identical and followed a $2 \times 2$ factorial design with the between-subjects factors: strain (DBA/2 vs. C57BL/6) and pre-exposure (PE vs. nPE). These factors were counterbalanced across the four shuttle boxes. Each experiment comprised two phases, pre-exposure and conditioning, conducted $24 \mathrm{~h}$ apart.

On the pre-exposure day, the animals in the pre-exposed (PE) condition received either 50 or 100 exposures to the to-be-conditioned white noise (experiments $3 \mathrm{~A}$ and $3 \mathrm{~B}$, respectively) presented at a variable inter-stimulus interval of $40 \mathrm{~s}$ (ranging from 25 to $55 \mathrm{~s}$ ), whilst the non-pre- 
exposed (nPE) subjects spent an equivalent amount of time in the shuttle boxes without any programmed events except for the house light.

On the next day, the animals were returned to the same boxes and received 100 active avoidance trials presented according to a random interval schedule (mean $40 \mathrm{~s}$, ranging from 25 to $55 \mathrm{~s}$ ). A trial began with the onset of the white noise CS. If the animal shuttled within $5 \mathrm{~s}$ of CS onset, the CS was terminated and the animal did not receive any foot shock: This was scored as an avoidance response. Avoidance failure led to the immediate delivery of a foot shock (presented in conjunction with the white noise CS) that could last for a maximum of $2 \mathrm{~s}$. A shuttle response during this period would terminate both the CS and the foot shock, and an escape response would be recorded. Otherwise, when an animal failed to shuttle in the presence of the shock, an escape failure was recorded. Shuttle responses performed during the inter-trial intervals were all without programmed consequence, but these were recorded and analysed separately. Avoidance learning was indexed by the number of successful avoidance responses across successive blocks of ten trials. Retarded learning in the PE subjects relative to the respective nPE controls would constitute LI.

Locomotor response to psychostimulant drugs in the open field

Apparatus The apparatus consisted of eight identical open field arenas constructed from plastic laminated wood with a waterproof white finish. Each arena measured $40 \times 40 \mathrm{~cm}$ in surface area and was surrounded on all sides by a $30-\mathrm{cm}-$ high wall. The experiment was conducted in two separate testing rooms with diffused dim lighting (30 lx). Each room housed four open field arenas positioned directly under a digital camera that captured images from all four arenas at a rate of $5 \mathrm{~Hz}$. The images were transmitted to a personal computer (PC) running the Ethovision (Noldus Technology, The Netherlands) tracking system, and locomotor activity was indexed by the cumulative displacement of the centre of gravity of the subject's surface area over successive frames, expressed in 10-min bins.

Procedures The allocation of animals between the two testing rooms and amongst the eight arenas was counterbalanced with respect to strains and drug conditions. Immediately following the systemic injection (amphetamine, PCP or saline vehicle), each animal was gently placed in the centre of the appropriate arena and allowed to explore undisturbed for $2 \mathrm{~h}$. They were not previously habituated to the arena because we intended to capture the unique profile of psychostimulant drug in association with environmental novelty - an aspect that is critical to both latent inhibition and prepulse inhibition on theoretical grounds (e.g. Schmajuk and Larrauri 2005; Schmajuk et al. 1996). Afterwards, they were returned to the home cage and the arenas cleansed with water and dried prior to the next squad. All solutions for injection were freshly prepared on the day of testing and administered in a volume of $5 \mathrm{ml} / \mathrm{kg}$ body weight via the i.p. route. Amphetamine (obtained from Sigma-Aldrich, Switzerland) and phencyclidine (PCP, donated by the National Institute for Drug Addiction, USA) were dissolved in sterile physiological saline to achieve the required doses of 2.5 and $5 \mathrm{mg} / \mathrm{kg}$, respectively.

\section{Statistical analysis}

All data were analysed by parametric analysis of variance (ANOVA) using the between-subject factors, strain, in combination with drug and pre-exposures as appropriate. Additional within-subject factors (e.g. 10-min bins, ten-trial blocks) were also included according to the nature of the considered dependent variables. To assist interpretation of the statistical outcomes, significant effects were further investigated by supplementary restricted analyses applied to a subset of the data or by pairwise comparisons based on the associated error terms taken from the overall ANOVA whenever appropriate. To better conform to the normality and variance homogeneity assumptions of parametric ANOVA, logarithmic transformation (indicated as "lntransformed" in the text and figures) was applied to the reactivity data in the prepulse inhibition experiment [ $1 \mathrm{n}$ (reactivity score $+e)-1$ ] (see Csomor et al. 2008). A square-root transformation was likewise applied to the number of inter-trial interval (ITI) crossings in the active avoidance experiment as well as to the activity measure in the open field experiment. All statistical analyses were carried out using SPSS for Windows (release 13, SPSS, Chicago IL, USA) implemented on a PC running the Windows XP (SP3) operating system.

\section{Results}

Experiment 1: comparison of baseline PPI expression in DBA/J2 and C57BL/6 mice

Here, both the expression of PPI and the acoustic startle reflex were comprehensively evaluated using the parametric design adopted from Yee et al. (2005) because of the anticipated between-strain difference in startle reactivity. Different data sets were derived from the test session and subjected to separate analyses to address specific processes as follows: (1) Startle reactions obtained in the first and last 
blocks of trials consisting only of pulse-alone trials were used to assess startle habituation. (2) Evaluation of the reaction to pulse-alone trials presented in the intermediate block of trials, when they were intermixed with different trial-types, allowed the assessment of startle reactivity that would be expected to affect PPI assessment. (3) PPI inhibition or reduction of startle reaction to the pulse stimulus induced by a preceding prepulse stimulus was assessed in an analysis of all pulse-alone and prepulse-pluspulse trials presented in the intermediate trial block. (4) PPI expression as percent reduction of the startle response (\% PPI) was included here for the purpose of comparison with previous studies that rely solely on this indexation of PPI, although there are serious reservations for its application when startle reactivity differed between treatment groups (Csomor et al. 2008; Swerdlow et al. 2000; Yee et al. 2005).

(5) Whenever appropriate and feasible, additional comparisons of PPI between strains were conducted with an attempt to balance the reactivity on pulse-alone trials by contrasting the data derived from one pulse intensity in one strain to the data obtained with another pulse intensity in the other strain. This entire analytic approach was adopted in experiments 1 and 2 . All reactivity scores were subjected to a logarithmic transformation (ln-transformed) prior to statistical analysis as explained in "Materials and methods" (also see Csomor et al. 2008; Yee et al. 2005).

\section{Startle habituation}

The first and the last six trials of the test session comprised only pulse-alone trials (two trials per intensity: 100, 110 or $120 \mathrm{~dB}_{\mathrm{A}}$ ). Comparison between these two blocks of six trials allowed the assessment of long-term startle habituation. As illustrated in Fig. 2a, a marked decrease in the startle reaction from the first to the last blocks was apparent in the DBA/2 mice, but not in the C57BL/6 mice. Whereas startle habituation was present in DBA/2 mice regardless of pulse stimulus intensity, $\mathrm{C} 57 \mathrm{BL} / 6$ mice displayed no obvious tendency of habituation. If anything, C57BL/6 mice showed a tendency of sensitisation to the pulse stimulus at the two lower intensities from the first to the last blocks. These impressions were confirmed by a $2 \times 2 \times 3$ (strain $\times$ blocks $\times$ pulse intensity) split-plot ANOVA, which yielded a significant strain by blocks interaction $[F(1,47)=$ $51.64, p<0.001]$, and the three-way interaction $[F(2,148)=$ $9.44, p<0.001]$. These were accompanied by a main effect of blocks $[F(1,74)=24.56, p<0.001]$, of pulse intensity $[F(1,74)=95.28, p<0.001]$ and of $\operatorname{strain}[F(1,74)=8.57, p=$ $0.005]$, indicating the overall presence of a habituation effect and the monotonic dependency of startle reaction on pulse intensity and that the two strains differed in startle reactivity. Supplementary analyses restricted to each strain confirmed the presence of a significant habituation effect in the DBA $/ 2$ strain [blocks: $F(1,39)=66.38, p<0.001$ ], but not in the $\mathrm{C} 57 \mathrm{BL} / 6$ strain $[F(1,35)=2.92, p=0.10]$.

\section{Startle reaction in pulse-alone trials in the main block}

The reaction obtained in pulse-alone trials in the main block (i.e. as apart from the first and last blocks of pulse-alone trials described above) was used in the assessment of PPI and was therefore analysed separately. The results confirmed the overall difference between the two mouse strains and that this strain difference was proportional to the intensity of the pulse stimulus (Fig. 2b, shaded region). These interpretations were supported by a $2 \times 3$ (strain $\times$ pulse intensity) split-plot ANOVA, which yielded a significant main effect of strain $[F(1,74)=19.72, p<0.001]$, pulse intensity $[F(2,148)=$ $169.75, p<0.001]$ as well as their interaction $[F(2,148)=$ $41.23, p<0.001]$. Pairwise comparisons based on the error variance associated with the significant interaction term confirmed the presence of a significant strain difference under the 110- and $120-\mathrm{dB}$ conditions $(p<0.0001)$, but not in the lower intensity $(100 \mathrm{~dB})$ condition.

\section{Prepulse inhibition: pulse-alone vs. prepulse-plus-pulse trials}

PPI is defined as the reduction of startle reaction to the pulse stimulus when it is preceded by a prepulse stimulus, relative to when it is not. Here, this was statistically assessed using a within-subject factor that incorporated both trial types as well as prepulse intensity, $+0,+6,+12$ and $+18 \mathrm{~dB}$, with +0 effectively referring to the pulse-alone condition. This is the recommended method in analysing treatment effects known to be confounded by a difference in startle reactivity (Swerdlow et al. 2000).

As illustrated in Fig. 2b, the presence of PPI was evident in both DBA/2 and C57BL/6 mice and across the three pulse intensities. Increasing prepulse intensity (from " +0 " representing pulse-alone condition) led to a monotonic reduction in startle magnitude, and this reduction appeared more pronounced in conditions with higher pulse intensity. The steepness of the individual curves depicted may be interpreted as the efficacy of the increasingly intense prepulse stimulus to inhibit more strongly the startle response elicited by the pulse stimulus (see Yee et al. 2004b). Thus, the depiction represented by Fig. $2 b$ suggests that $\mathrm{DBA} / 2$ mice were in general less responsive to the prepulse.

A $2 \times 3 \times 4$ (strain $\times$ pulse intensity $\times$ prepulse intensity) split-plot ANOVA revealed a significant main effect of pulse intensity $[F(2,148)=229.05, p<0.001]$, as expected. The presence of a significant prepulse intensity effect $[F(3,222)=240.80, p<0.001]$ and its interaction with pulse intensity $[F(6,444)=10.26, p<0.001]$ confirmed the presence of PPI and its dependency on pulse intensity. The 
a

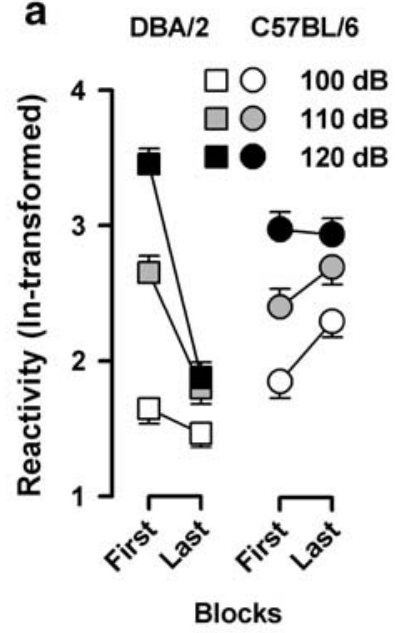

c

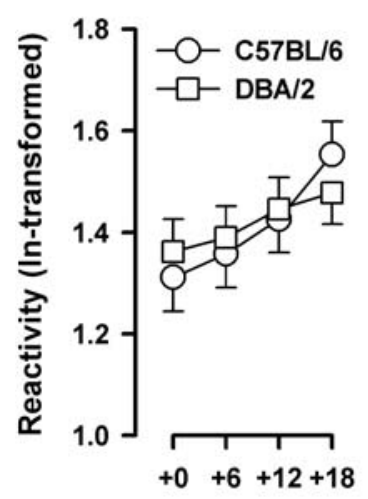

Prepulse (dB units above background) b

Pulse $=100 \mathrm{~dB}$

Pulse=110dB

Pulse $=120 \mathrm{~dB}$
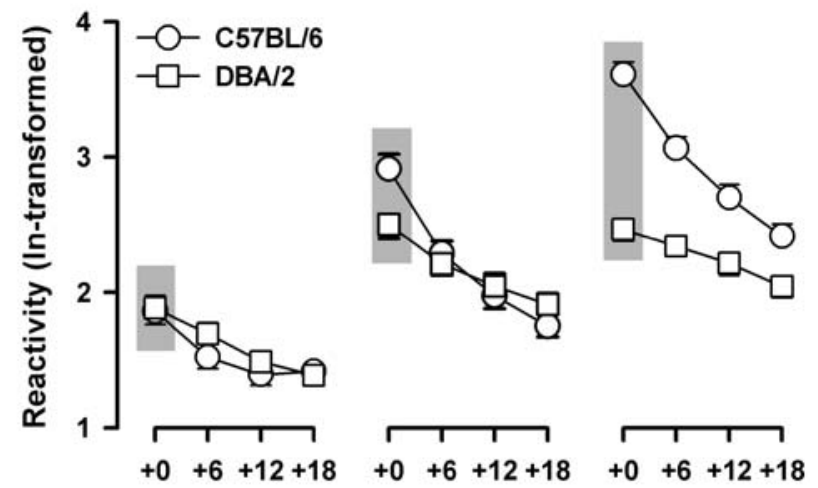

Prepulse (dB units above background)

d

Pulse $=100 \mathrm{~dB}$

Pulse $=110 \mathrm{~dB}$

Pulse $=120 \mathrm{~dB}$
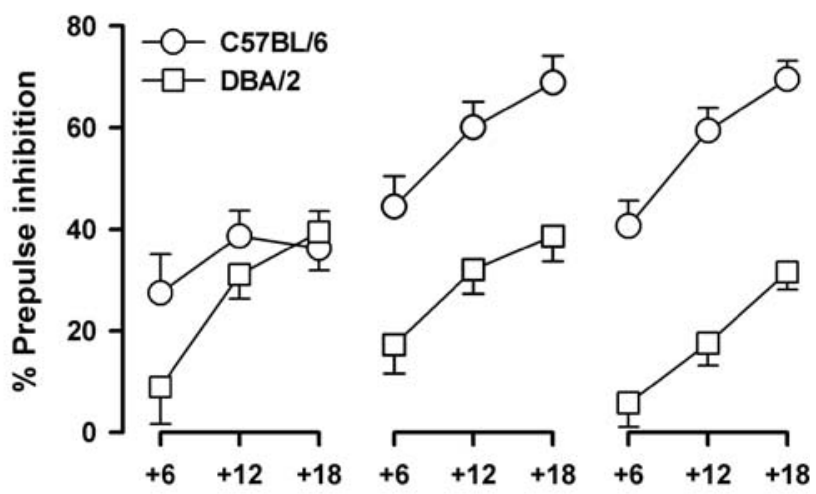

Prepulse (dB units above background)
Fig. 2 Summary of the results in experiment 1. Based on the PPI test session, the following data sets were derived and separately analysed. a Comparison between the first and last blocks of the test session comprising pulse-alone trials only with two trials of each pulse intensity $\left(100,110\right.$ and $120 \mathrm{~dB}_{\mathrm{A}}$, represented by increasing shades of grey). Results of the two strains were plotted separately (left, DBA/2; right, C57BL/6). b Average reactivity scores (following logarithmic transformation) across 12 different types of trial definition obtained in the intermediate block of the test session: pulse-alone trials (emphasised by the shaded rectangular background) are denoted as " $+0 \mathrm{~dB}$ " in the abscissa. The intensity of the prepulse stimulus in prepulse-

analysis also revealed significant differences between mouse strains. The significant main effect of strain $[F$ $(1,74)=11.65, p<0.05]$ and its interaction with pulse intensity $[F(2,148)=34.28, p<0.001]$ are in keeping with the impressions obtained from the preceding analysis: DBA $/ 2$ mice showed reduced overall startle reactivity, and this strain difference was dependent on pulse intensity. Concerning the comparison of PPI expression between strains, the analysis also revealed a significant strain by prepulse intensity interaction $[F(3,222)=24.05$, $p<0.001]$ and the three-way interaction $[F(6,444)=10.26$, plus-pulse trials was also denoted along the abscissa as $+6,+12$ and +18 decibel units above the constant background noise level of $65 \mathrm{~dB}_{\mathrm{A}}$. Three separate plots were illustrated corresponding to the three pulse stimulus intensities: 100,110 and $120 \mathrm{~dB}_{\mathrm{A}}$, as indicated at the top. c Response (again following a logarithmic transformation) obtained in prepulse-alone trials (of three intensities) and in comparison to "nostimulus" trials. d Results in percent prepulse inhibition (\%PPI) derived from the same data set as illustrated in b. Circles, C57BL/6 strain; squares, DBA/2 strain (regardless of fillings). All values are means with associated standard errors $( \pm \mathrm{SE})$ based on the respective ANOVA conducted using SPSS for Windows (version 13)

$p=0.001]$. These effects support the conclusion that in $\mathrm{DBA} / 2$ mice, responsiveness to the prepulse was attenuated, and this attenuation was dependent on pulse intensity, apparently more pronounced at higher than lower pulse intensities.

Startle-matched and cross-pulse intensity analysis of PPI: pulse-alone vs. prepulse-plus-pulse trials

Because response in pulse-alone trials was highly comparable between strains at the lowest pulse $(100 \mathrm{~dB})$, a 
restricted ANOVA was performed on data derived from this particular test condition. As expected, the main effect of strain was no longer significant $(F<1)$. The PPI effect was confirmed by the presence of a significant main prepulse effect $[F(3,222)=45.11, p<0.001]$. However, evidence of a PPI deficit in the DBA/2 mice was weaker: The strain by prepulse intensity interaction failed to achieve statistical significance $[F(3,222)=1.90, p=0.13]$. Only the quadratic trend of this interaction remained statistically significant $[F(1,74)=5.00, p<0.05]$. Hence, there is tentative evidence that $\mathrm{DBA} / 2$ mice exhibited a PPI deficiency relative to C57BL/6 mice independent of the confounding reduction in startle reactivity.

As a further and more stringent test of this assertion, we next selected for comparison between the two strains the highest pulse intensity $(120 \mathrm{~dB})$ data set from DBA/ 2 mice and the lowest pulse intensity $(100 \mathrm{~dB})$ data set from $\mathrm{C} 57 \mathrm{BL} / 6$ mice. This effectively reversed the difference in pulse-alone reaction between strains. A $2 \times 4$ (strain $\times$ pre-pulse intensity) split-plot ANOVA of this data set revealed again a significant interaction between strain and prepulse $[F(3,222)=4.40, p<0.005]$, which still supports the interpretation that the startle response in DBA/2 mice was less sensitive to the inhibition by the prepulse. The significant main effect of strain $[F(1,74)=38.06, p<0.001]$ in this analysis now refers to overall startle response being higher in the DBA/ 2 mice. The main effect of prepulse was also significant $[F(3,222)=42.64, p<0.001]$, indicating the overall presence of PPI.

\section{Prepulse inhibition: percent startle inhibition}

In conformity to the common method of PPI indexation by percent startle reduction calculated with respect to the corresponding pulse-alone condition, we also presented our data using the expression \%PPI $=$ (pulse-alone prepulse-plus-pulse)/pulse-alone $\times 100 \%$ ) using the untransformed reactivity scores for each of the nine (three prepulse intensities $\times$ three pulse intensities) prepulseplus-pulse conditions (see Fig. 2d). A $2 \times 3 \times 3$ (strain $\times$ pulse intensity $\times$ prepulse intensity) split-plot ANOVA of \%PPI revealed an overall strain effect $[F(1,74)=38.40$, $p<0.001]$, which is suggestive of a PPI deficit in the $\mathrm{DBA} / 2$ mice. Dependency of this deficit on pulse intensity was supported by the strain by pulse intensity interaction $[F(2,148)=5.79, p<0.005]$, which was accompanied by a significant main effect of pulse intensity $[F(2,148)=8.00, p<0.001]$. The main effect of prepulse intensity also achieved significance $[F(2,148)=77.66, p<$ $0.001]$, confirming that increasing prepulse intensity led systemically to stronger PPI. However, there was no statistical evidence in this analysis that this effect of prepulse intensity was modified by startle intensity (pulse by prepulse interaction: $F<1$ ).

Startle-matched and cross-pulse intensity analysis: percent startle inhibition

In parallel with the preceding analysis, a supplementary analysis on the \%PPI measure restricted to the lowest pulse $(100 \mathrm{~dB})$ condition when the pulse-alone reaction was comparable between the two mouse strains was conducted. This effectively circumvented the inappropriateness of using \%PPI measure under situations of pronounced startle difference between groups. This $2 \times 3$ (strain $\times$ prepulse intensity) split-plot ANOVA revealed a main effect of prepulse intensity $[F(2,148)=12.24, p<0.001]$ and its interaction with strain $[F(2,148)=3.26, p<0.05]$. The latter suggests that DBA/2 PPI deficiency is not dependent on the confounding reduction in startle reactivity observed at the higher pulse intensities (Fig. 2b, d).

Next, we conducted the cross-pulse intensity analysis on the \%PPI measure, as performed above on the reactivity data. To this end, the \%PPI data derived from the highest pulse intensity $(120 \mathrm{~dB})$ data set of the DBA/2 mice were compared with that derived from the lowest pulse intensity $(100 \mathrm{~dB})$ data set of the C57BL/6 mice. A $2 \times 3$ (strain $\times$ pulse intensity) split-plot ANOVA of this $\%$ PPI data set also provided evidence for a relative PPI deficiency in DBA/2 mice. This analysis yielded a significant main effect of strain $[F(1,74)=6.51, p<0.05]$, prepulse $[F(2,148)=6.51, p<0.001]$ as well as their interaction $[F(2,148)=3.43, p<0.05]$.

\section{Reaction to prepulse-alone trials}

Direct response to the prepulse stimulus can be of relevance to the evaluation of changes in PPI expression (Csomor et al. 2009; Yee and Feldon 2009; Yee et al. 2004a, b, 2005). In comparison with the "no-stimulus" control condition, the prepulse led to a monotonic increase in motor reaction (Fig. 2c). This was largely comparable between the two mouse strains. A $2 \times 4$ (strain $\times$ prepulse intensity) split-plot ANOVA of the ln-transformed mean reactivity scores yielded only a significant main effect of prepulse intensity $[F(3,222)=8.47, p<0.001]$.

\section{Influence of body weight on startle reaction and PPI expression}

A difference in body weight represents a potential confound in the measurement of startle response using piezoelectric accelerometers to detect change in the animal's whole body momentum. The body weight of all subjects was therefore recorded prior to the PPI experiment and was highly 
comparable between strains. The mean $( \pm$ SEM $)$ body weight was: $\mathrm{C} 57 \mathrm{BL} / 6=27.6 \pm 0.4 \mathrm{~g}, \mathrm{DBA} / 2=27.0 \pm 0.4 \mathrm{~g}$. A one-way ANOVA failed to reveal a significant strain effect $[F(1,74)=1.01, p=0.32]$. It is therefore unlikely that the divergence between the two strains in PPI expression and startle reaction could be attributable solely to differences in body weight.

Experiment 2: effects of clozapine on PPI expression in $\mathrm{C} 57 \mathrm{BL} / 6$ and $\mathrm{DBA} / 2$ mice

\section{Startle habituation}

The finding of a strain-dependent habituation effect was replicated, along with overall strain difference in startle reactivity and the effect of pulse intensity. The results are summarised in Table 1.

In keeping with the outcomes of experiment 1 , a $2 \times 2 \times$ $2 \times 3$ (strain $\times$ drug $\times$ blocks $\times$ pulse intensity) split-plot ANOVA of the (ln-transformed) startle reactivity obtained in the first and last blocks of the test session yielded a main effect of blocks $[F(1,34)=5.01, p<0.05]$, pulse intensity $[F(2,68)=67.44, p<0.001]$, strain $[F(1,34)=$ $36.95, p<0.001]$ and the strain $\times$ blocks $[F(1,34)=36.17$, $p<0.001]$ as well as strain $\times$ pulse intensity interaction $[F(2,64)=28.24, p<0.001]$. The directions of all these effects were consistent with those observed in experiment 1. In addition, clozapine treatment did not affect startle habituation (drug $\times$ block interaction: $F<1$ ), nor did it affect the overall levels of startle reactivity [drug: $F(1,34)=2.07, p=$ $0.16]$. However, there was a tendency that clozapine pretreatment weakened reaction to the highest pulse stimulus [drug $\times$ pulse intensity: $F(2,68)=2.75, p=0.07$ ] This trend is worth noting in view of the following analysis.

\section{Startle reaction on pulse-alone trials in the main block}

Again, the critical findings concerning strain differences were in agreement with the outcomes of experiment 1 . Briefly, DBA/2 mice exhibited reduced startle reaction, and this reduction was more pronounced at the higher pulse intensities (see Fig. 3a, b). A $2 \times 2 \times 3$ (strain $\times$ drug $\times$ pulse intensity) split-plot ANOVA of pulse-alone trials derived from the middle block yielded a highly significant main effect of strain $[F(1,34)=65.71, p<$ $0.001]$ and its interaction with pulse intensity $[F(2,68)=$ $23.55, p<0.001]$. In addition, clozapine significantly affected startle reactivity, and this drug effect also depended on the intensity of the pulse stimulus. The main effect of drug approached statistical significance $[F(1,34)=3.84, p=0.06]$, and the drug by pulse intensity interaction was highly significant $[F(2,68)=5.38, p<0.01]$.

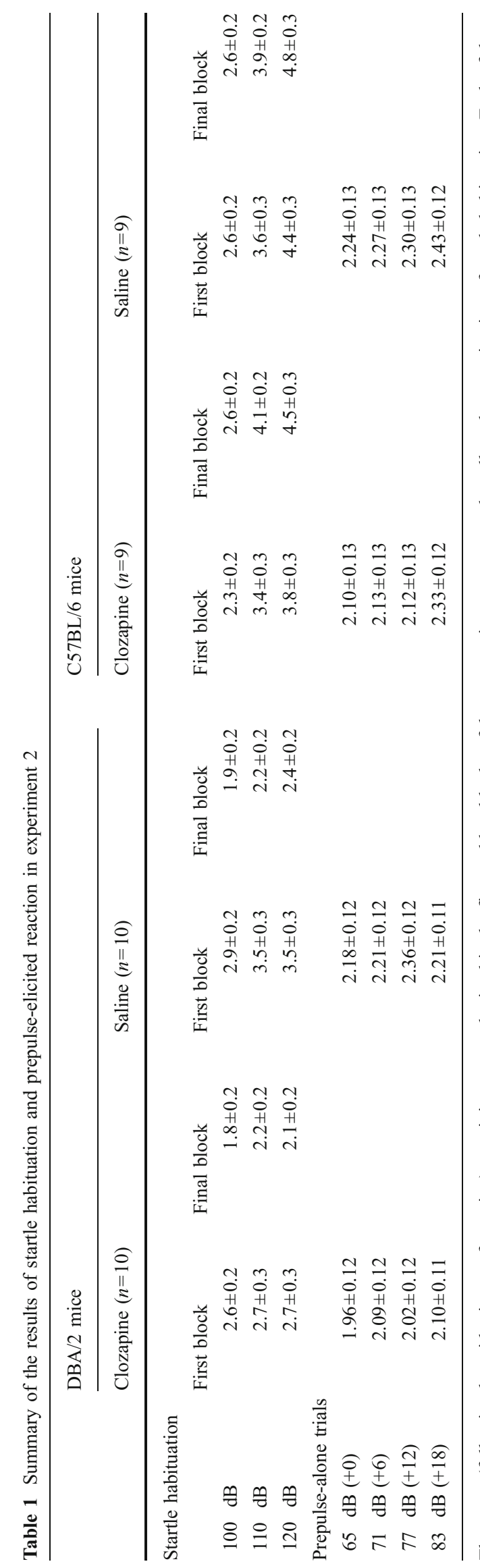




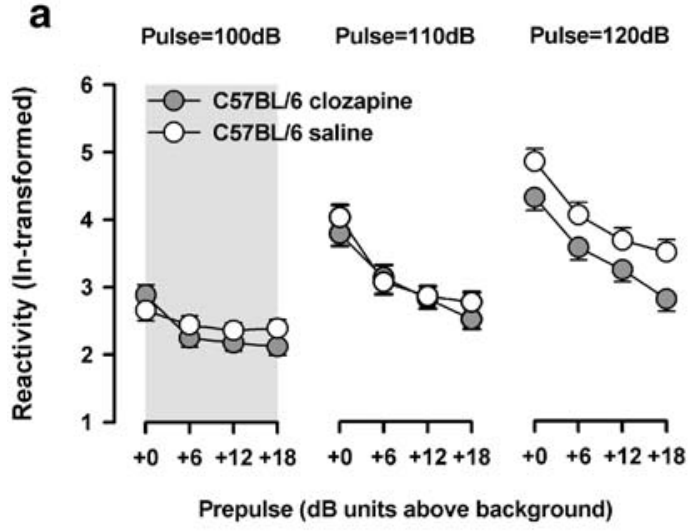

C

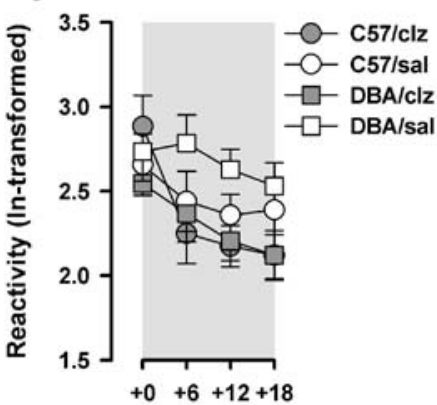

d

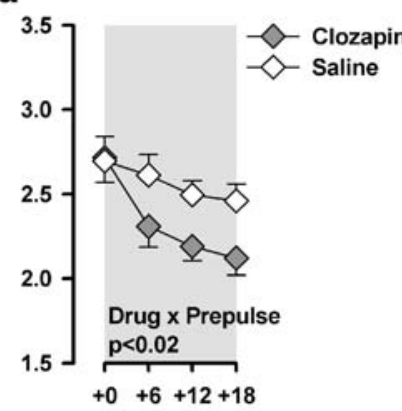

Prepulse (dB units above background)

Fig. 3 Summary of the results in experiment 2. The average reactivity scores (following logarithmic transformation) across 12 different types of trial definition obtained in the intermediate block of trials for C57BL/6 mice and DBA/2 mice are depicted in $\mathbf{a}$ and $\mathbf{b}$, respectively. Pulse-alone trials are denoted as " $+0 \mathrm{~dB}$ " in the abscissa. The intensity of the prepulse stimulus in prepulse-plus-pulse trials was also denoted along the abscissa as $+6,+12$ and +18 decibel units above the constant background noise level of $65 \mathrm{~dB}_{\mathrm{A}}$. Within $\mathbf{a}$ and $\mathbf{b}$, three separate plots are illustrated corresponding to the three pulse stimulus intensities: 100,110 and $120 \mathrm{~dB}_{\mathrm{A}}$, as indicated at the top. The shaded regions in a and $\mathbf{b}$ highlight the respective pulse conditions between the two mouse

Similar to the effect of strain, the startle-attenuating effect of clozapine was more notable at higher pulse stimulus intensities, and this drug effect was apparent in both mouse strains. Pairwise comparisons based on the error variance associated with the significant drug by pulse intensity interaction indicate that clozapine pretreatment led only to a significant reduction in startle reactivity at the pulse $=120-\mathrm{dB}$ condition .

\section{Prepulse inhibition}

Confronted with a significant effect on startle reactivity of clozapine treatment as well as between strains, analysis of PPI expression by means of percent inhibition would be highly problematic. Hence, we again adopted the analytical approach in experiment 1 and conducted a $2 \times 2 \times 3 \times 4$ (strain $\times$ drug $\times$ pulse intensity $\times$ prepulse intensity) ANOVA of the ln-transformed reactivity scores obtained

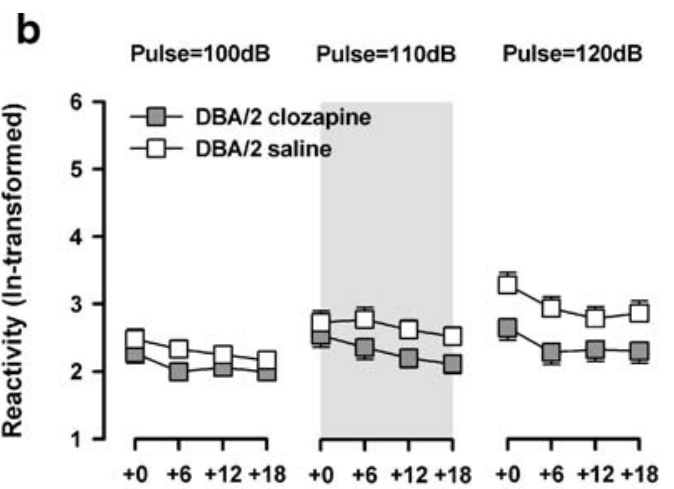

Prepulse (dB units above background)

e
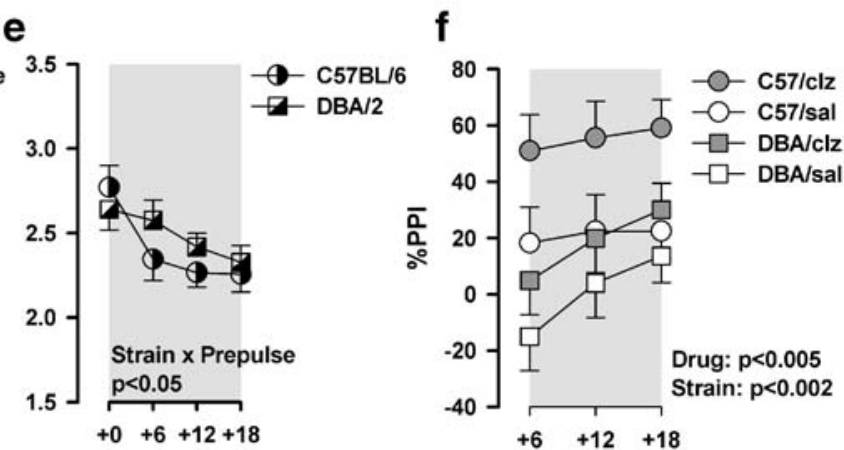

Prepulse (dB units above background)

strains, which are explicitly compared in all subsequent figures $(\mathbf{c}-\mathbf{f})$. $\mathbf{c}$ Cross-pulse intensity (startle-matched) comparison amongst the four strain $\times$ drug conditions. d Drug effect derived from this startlematched comparison by contrasting the two drug conditions (clozapine vs. saline) collapsed across strains. e Strain difference collapsed across drug conditions. f Results expressed in percent inhibition (\% PPI) derived from this startle-matched comparison. All mean values are illustrated with the associated standard errors $( \pm \mathrm{SE})$ obtained from the respective ANOVA conducted using SPSS for Windows (version 13). clz clozapine, sal saline, $C 57 \mathrm{C} 57 \mathrm{BL} / 6$ strain, $D B A \mathrm{DBA} / 2$ strain

in both pulse-alone and prepulse-plus-pulse conditions (see Fig. 3a, b).

The analysis yielded a main effect of pulse intensity $[F(2,68)=93.58, p<0.001]$, as expected. The overall presence of PPI and its dependence on pulse intensity were evident from the significant effect of prepulse intensity $[F(3,102)=164.05, p<0.001]$ and its interaction with pulse intensity $[F(6,204)=8.37, p<0.001]$, respectively. A number of significant effects and interactions that emerged are consistent with strain- and drug-induced differences in startle reactivity as seen already in the previous two analyses: strain $[F(1,34)=27.97, p<0.001]$, strain $\times$ pulse intensity $[F(2,68)=20.46, p<0.001]$, strain $\times$ pulse intensity $\times$ prepulse intensity $[F(6,204)=26.74, p<0.001]$, drug $[F(1,34)=$ $6.99, p<0.05]$ and drug $\times$ pulse intensity $[F(2,68)=4.82, p<$ $0.05]$. As in experiment 1 , the interaction between strain and prepulse attained statistical significance $[F(3,102)=45.27, p<$ $0.001]$, suggesting that the reactivity to the pulse stimulus was 
less modified by the prepulse stimulus in DBA/2 mice than in C57BL/6 mice (see Fig. 3a, b).

However, the analysis yielded no suggestion that clozapine treatment had modified the expression of PPI in either strain. Neither the drug by prepulse intensity interaction $[F(3,102)=1.44, p=0.24]$ nor other higher interaction terms consisting of these two factors achieved statistical significance.

We next conducted an additional analysis in an attempt to balance the startle reactivity across different betweensubjects conditions. To this end, the data (reactivity scores obtained from pulse-alone and prepulse-plus-pulse trials) derived from the pulse $=110-\mathrm{dB}$ condition in DBA $/ 2$ mice and the data derived from the pulse $=100-\mathrm{dB}$ condition in C57BL $/ 6$ mice were combined into a $2 \times 2 \times 4$ (strain $\times$ drug $\times$ prepulse intensity) ANOVA (see Fig. $3 \mathrm{c}-\mathrm{e}$ ). As expected, neither the main effects of strain nor drug were significant, and the highly significant main effect of prepulse intensity $[F(3,102)=17.46, p<0.001]$ indicated the presence of PPI. Most critically, this analysis yielded a clear presence of a drug $\times$ prepulse intensity $[F(3,102)=$ $3.62, p<0.05]$ and strain $\times$ prepulse intensity interaction $[F(3,102)=3.07, p<0.05]$. These two interaction effects are depicted separately in Fig. 3d and e, respectively, showing that clozapine exerted an overall PPI-enhancing effect, whereas DBA/2 mice showed a reduction in PPI expression relative to $\mathrm{C} 57 \mathrm{BL} / 6$ mice. Figure $3 \mathrm{c}$ shows that the clozapine treatment effect was present in both mouse strains.

Next, this specific startle-matched data set (comprising data derived from the lowest pulse condition from C57BL/6 mice and the middle pulse condition from DBA/2 mice) was expressed as percent inhibition (\%PPI) since the startle reactivity on pulse-alone trials was now largely balanced (see Fig. 3f). The statistical outcomes complemented perfectly the impressions described above, yielding a significant effect of drug $[F(1,34)=9.14, p<0.005]$ and of strain $[F(1,34)=11.23, p<0.005]$. There was again no indication of any interaction between these two betweensubjects factors $(F<1)$.

\section{Reaction to prepulse-alone trials}

Separate analysis of the reaction to the prepulse-alone trials by a $2 \times 2 \times 4$ (strain $\times$ drug $\times$ prepulse intensity) ANOVA only yielded a significant main effect of prepulse intensity $[F(3,102)=3.60, p<0.05]$. Neither mouse strain nor clozapine pretreatment was associated with any significant change in prepulse-elicited reaction. The results are summarised in Table 1, instead of graphically because of the considerable overlap between conditions. The lack of a strain difference in this measure was consistent with the outcome from experiment 1 . The absence of a drug effect was instrumental in showing that it had not altered the direct perception or reaction to the prepulse stimuli.

Experiment 3A: strong latent inhibition of active avoidance learning (100 pre-exposures of the CS)

\section{Pre-exposure day}

The total number of shuttle responses recorded in the preexposure phase was subjected to a two-way (strain $\times$ stimulus pre-exposure) ANOVA following a square-root transformation. As a measure of activity, this yielded a significant effect of strain $[F(1,12)=10.69, p<0.01]$, with $\mathrm{DBA} / 2$ mice performing significantly more spontaneous shuttles than $\mathrm{C} 57 \mathrm{BL} / 6$ mice. On the other hand, this measure was not affected $(F<1)$ by whether the animals were in the PE or nPE condition. The mean (square-roottransformed) total numbers of shuttles recorded in each of the four groups were: $\mathrm{DBA} / 2-\mathrm{nPE}=15.77, \mathrm{DBA} / 2-\mathrm{PE}=$ 15.18, C57BL/6-nPE $=11.26, \mathrm{C} 57 \mathrm{BL} / 6-\mathrm{PE}=12.01 \quad$ (standard error of differences, $\mathrm{SED}=1.18$ ).

\section{Conditioning day}

Stimulus pre-exposure resulted in an attenuation of avoidance learning on the conditioning day, constituting the LI effect. LI was readily detected in the C57BL/6 mice, but was distinctly absent in the DBA/2 mice (see Fig. 4a). A $2 \times 2 \times 10($ strain $\times$ stimulus pre-exposure $\times 10$-trial blocks $)$ split-plot ANOVA of avoidance successes yielded a significant effect of blocks $[F(9,108)=21.01, p<0.001]$ indicative of a general improvement of avoidance performance over successive blocks of training. The main effect of pre-exposure approached statistical significance $[F$ $(1,12)=4.34, p=0.06]$, which could be considered as significant, however, if a one-tailed criterion is adopted, given that expectation of an LI effect has specified the direction of the pre-exposure effect. Finally, the interaction between strain and pre-exposure just reached the margin of statistical significance $[F(1,12)=4.58, p<0.05]$. Pairwise comparisons confirmed the presence of a significant LI effect in the C57BL/6 mice $(p<0.05)$, but not in the DBA/2 mice. Comparison between strains restricted to either preexposure condition did not yield any significant differences, suggesting that the loss of $\mathrm{LI}$ in the $\mathrm{DBA} / 2$ mice was attributable to the combined strain differences in both $\mathrm{PE}$ and nPE conditions.

The number of spontaneous shuttle responses recorded during the ITIs on the conditioning day was subjected to a $2 \times 2 \times 10$ (strain $\times$ stimulus pre-exposure $\times 10$-trial blocks) split-plot ANOVA following a square-root transformation. The results indicated that $\mathrm{DBA} / 2$ mice were more active 
a

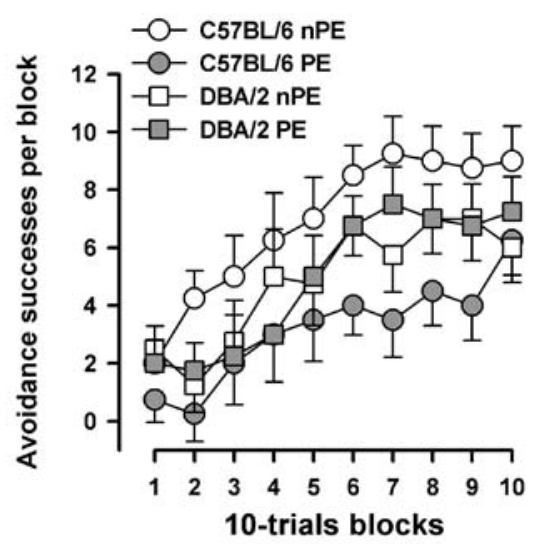

C

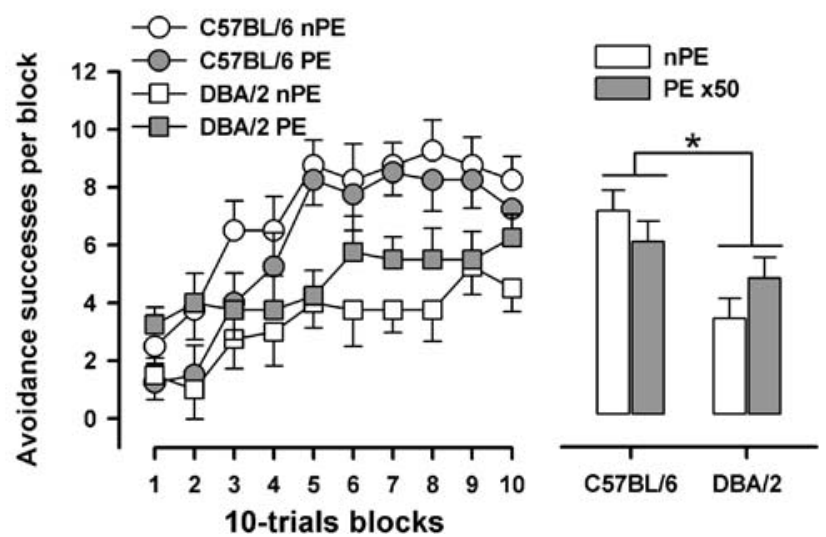

Fig. 4 Summary of the results in experiments $3 \mathrm{~A}$ and 3B. Two variables were obtained on the conditioning day. (1) The number of avoidance successes expressed as a function of successive ten-trial blocks (on the left) or collapsed across blocks (on the right) for experiment 3A (a) and Experiment 3B (c), respectively. (2) The number of spontaneous shuttle responses recorded in the inter-trial intervals (square-root-transformed) across successive ten-trial blocks or collapsed across blocks were likewise illustrated in $\mathbf{b}$ and $\mathbf{d}$ for experiments $3 \mathrm{~A}$ and $3 \mathrm{~B}$, respectively. Asterisk refers to a significant

and did not show any sign of reduction over the course of the test session as did the C57BL/6 mice (see Fig. 4b). Stimulus pre-exposure did not lead to any change in this spontaneous activity index. These impressions were confirmed by the significant effect of strain $[F(1,12)=61.07$, $p<0.001]$, blocks $[F(9,108)=13.25, p<0.001]$ and their interaction $[F(9,108)=8.37, p<0.001]$.

Experiment 3B: weak latent inhibition of active avoidance learning (50 pre-exposures of the CS)

\section{Pre-exposure day}

DBA/2 mice again performed more spontaneous shuttles than $\mathrm{C} 57 \mathrm{BL} / 6$ mice on the pre-exposure day regardless of pre-exposure condition. However, in this experiment, this effect just failed to achieve statistical significance. A two- b

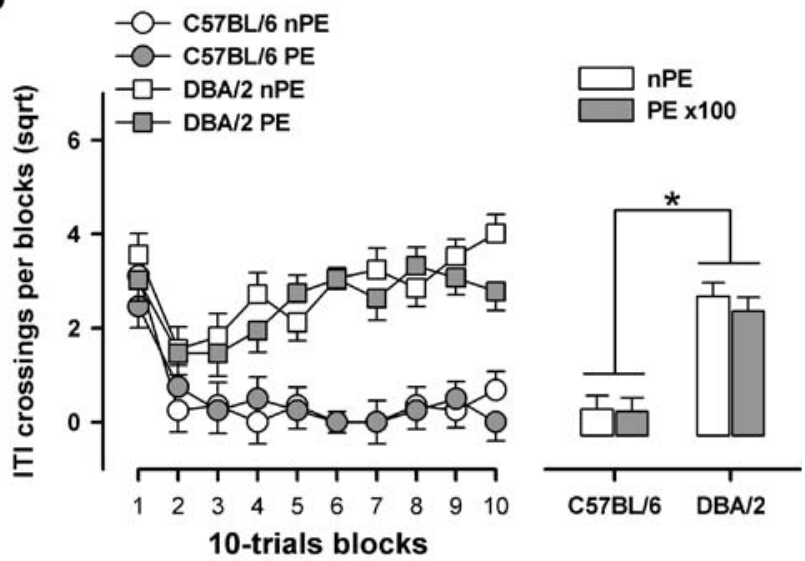

d

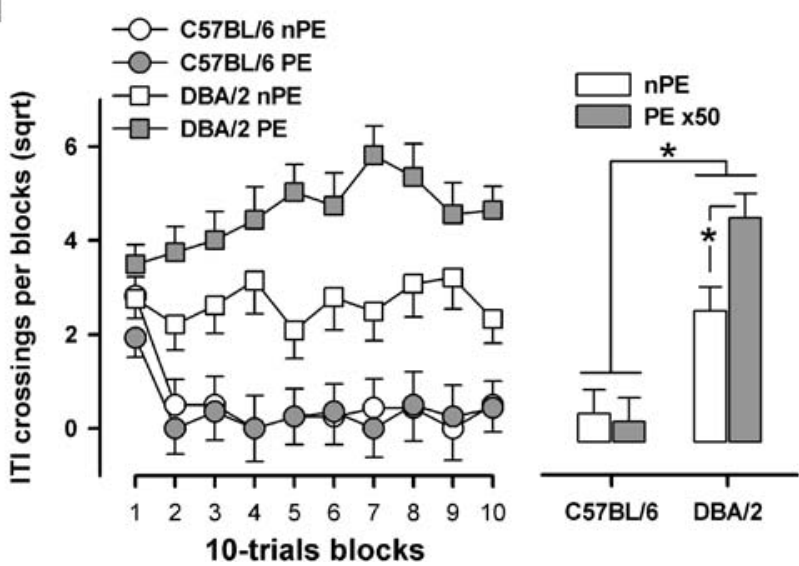

$(p<0.05)$ main effect of strain (in $\mathbf{b}-\mathbf{d})$ and, in addition, the selective presence of a significant pre-exposure effect in the avoidance learning in $\mathrm{C} 57 \mathrm{BL} / 6$ mice in experiment $3 \mathrm{~A}$ (shown in a) and a significant preexposure effect in the measure of inter-trial intervals spontaneous shuttles in DBA/2 mice (shown in d). All mean values are illustrated with the associated standard errors $( \pm \mathrm{SE})$ obtained from the respective ANOVA conducted using SPSS for Windows (version 13), which are appropriate for comparison between the illustrated mean values

way (strain $\times$ stimulus pre-exposure) ANOVA yielded a marginal effect of strain $[F(1,12)=4.14, p=0.06]$. No other effects including the interaction term were either close to or achieved statistical significance. The mean (square-roottransformed) numbers of total shuttles recorded in each of the four groups were: $\mathrm{DBA} / \mathrm{nPE}=7.97, \mathrm{DBA} / \mathrm{PE}=9.53$, $\mathrm{C} 57 / \mathrm{nPE}=7.70, \mathrm{C} 57 / \mathrm{PE}=7.20$ (standard error of differences, $\mathrm{SED}=0.64$ ).

\section{Conditioning day}

As expected, 50 stimulus pre-exposures did not lead to a significant LI effect in the C57BL/6 mice. Against this background, $\mathrm{DBA} / 2$ mice did not show any tendency to exhibit LI. If anything, the direction of the pre-exposure effect was opposite to that of the LI effect. Overall, DBA/2 mice now appeared to show a general impairment in 
avoidance learning in comparison to $\mathrm{C} 57 \mathrm{BL} / 6$ mice, which is consistent with the impression obtained in the $\mathrm{nPE}$ condition of experiment $3 \mathrm{~A}$. A $2 \times 2 \times 10$ (strain $\times$ stimulus pre-exposure $\times$ 10-trial blocks) split-plot ANOVA of avoidance successes revealed only a significant main effect of strain $[F(1,12)=12.53, p<0.005]$, of blocks $[F$ $(9,108)=26.76, p<0.001]$ and their interaction with blocks $[F(9,108)=10.78, p<0.001]$.

Analysis of spontaneous shuttles during ITIs again revealed a strain difference similar to that seen in experiment 3A: DBA/2 mice were hyperactive and their spontaneous shuttle activity failed to show any habituation. The main effect of strain $[F(1,12)=41.13, p<0.001]$, of blocks $[F(9,108)=2.55, p<0.05]$ and their interaction $[F$ $(9,108)=5.82, p<0.001]$ again emerged as being highly significant. In addition, the levels of spontaneous activity exhibited by DBA/2 mice in this experiment appeared also to be dependent on the pre-exposure condition - a tendency that was not present in experiment $3 \mathrm{~A}$, when twice as many CS-pre-exposures had been experienced by the PE animals on the previous day (i.e. in the pre-exposure phase). This resulted in a near-significant interaction between strain and pre-exposure $[F(1,12)=4.48, p=0.056]$, and pairwise comparisons revealed that DBA/PE subjects performed significantly more spontaneous shuttles than subjects in all other conditions (minimal $p<0.02$ ).

Experiment 4: Motor stimulating effects of acute amphetamine or phencyclidine treatment

Activity in the open field under vehicle treatment condition confirmed the impression obtained in experiments $3 \mathrm{~A}$ and $3 \mathrm{~B}$ that $\mathrm{DBA} / 2$ mice were spontaneously more active than C57BL/6 mice (Fig. 5a). Indeed, the same animals in experiment 4 had participated in experiments $3 \mathrm{~A}$ and $3 \mathrm{~B}$. Both mouse strains responded to the psychostimulant drugs with an elevation of motor activity. Examination of the temporal expression of the drug effect suggest that DBA/2 mice responded more quickly to amphetamine, achieving peak response almost within the first $10 \mathrm{~min}$, whilst it took C57BL/6 mice nearly $30 \mathrm{~min}$ to reach peak response (Fig. 5b). The peak response magnitude appeared comparable between strains, and by the end of the 2-h observation period, activity between the two strains was comparable, but was still higher than their respective vehicle-treated controls. In contrast, the immediate response to acute PCP injection was highly comparable between $\mathrm{DBA} / 2$ and C57BL/6 mice. However, DBA/2 mice showed a sustained and elevated (relative to $\mathrm{DBA} /$ saline subjects) response throughout the $2-\mathrm{h}$ period, whereas activity levels in C57BL/6 mice showed a consistent (except from bins 8 to 9) monotonic reduction following the immediate peak (Fig. 5c). Hence, although DBA/2 mice showed some form of hyperresponsiveness to amphetamine and PCP in comparison to $\mathrm{C} 57 \mathrm{BL} / 6$ mice, the precise temporal dynamic of this strain difference differed substantially between the two pharmacologically distinct drugs.

The interpretations above were substantiated by the results of a $2 \times 3 \times 12$ (strain $\times$ drug $\times 10$-min bins) splitplot ANOVA of distance travelled (square-root-transformed) per bin. All main effects attained statistical significance: strain $[F(1,26)=34.73, p<0.001]$, drug $[F$ $(2,26)=74.64, p<0.001]$ and bins $[F(11,286)=15.00, p=$ $0.001]$. The presence of a strain by drug interaction $[F$ $(2,26)=6.85, p<0.005]$ and the three-way interaction $[F$ $(22,286)=3.90, p=0.001]$ confirmed the differences between strains in terms of their overall activity levels, and that the temporal profiles differed between the three drug conditions. Because the drug-induced activity profile differed between the two drugs (and in comparison to saline vehicle), the interaction between drug and bins was also highly significant $[F(22,286)=7.87, p<0.001]$.

Pairwise comparisons between strains under each treatment condition confirmed the impression that the two strains differed under vehicle condition $(p<0.001)$ and following PCP treatment $(p<0.001)$, but not when they were both under the influence of amphetamine $(p=0.60)$. The latter supported the interpretation that the two strains differed primarily in their temporal response to amphetamine. This emphasis was also confirmed by supplementary restricted analyses: A significant strain by bins interaction was only evident in the analyses restricted either to the amphetamine $[F(11,110)=2.29, p<0.05]$ or PCP $[F$ $(11,110)=8.03, p<0.001]$ conditions, whereas the strain difference was stable over time in the absence of a drug challenge (vehicle condition).

\section{Discussion}

The present study represents a comprehensive evaluation of the DBA/2 mouse strain in schizophrenia-related endophenotypes and its reaction to acute psychostimulant drug challenge in comparison to the $\mathrm{C} 57 \mathrm{BL} / 6$ strain. This strain comparison has revealed a number of behavioural divergences that may be interpreted as the presence of multiple schizophrenia-related traits in DBA/2 mice (or, alternatively, of an antipsychotic profile in C57BL/6 mice). This includes, first of all, the relative deficiency in prepulse inhibition and latent inhibition, which parallel that reported in schizophrenia patients (e.g. Baruch et al. 1988; Braff et al. 2001, 1992; Gray et al. 1992). The difference in motor response to acute psychostimulant drug challenge further indicates that dopaminergic as well as glutamatergic/ NMDA receptor functions also diverge between these two mouse strains. It is, however, premature to conclude that 
a
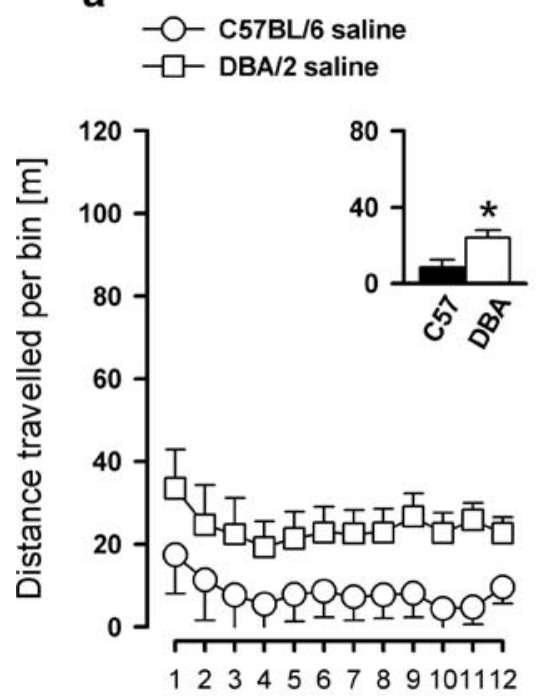

10-min bins b
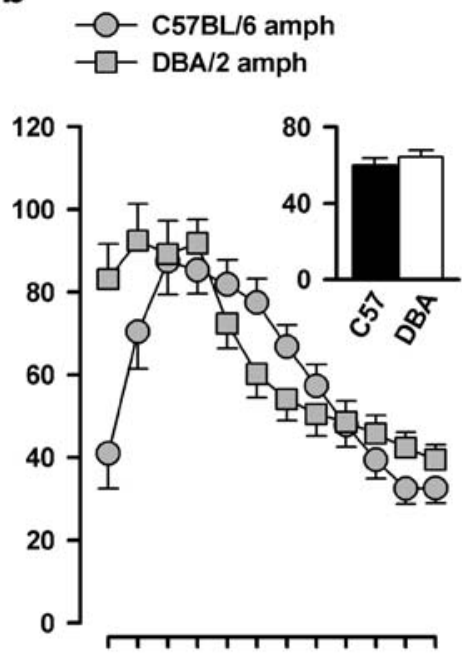

123456789101112

C
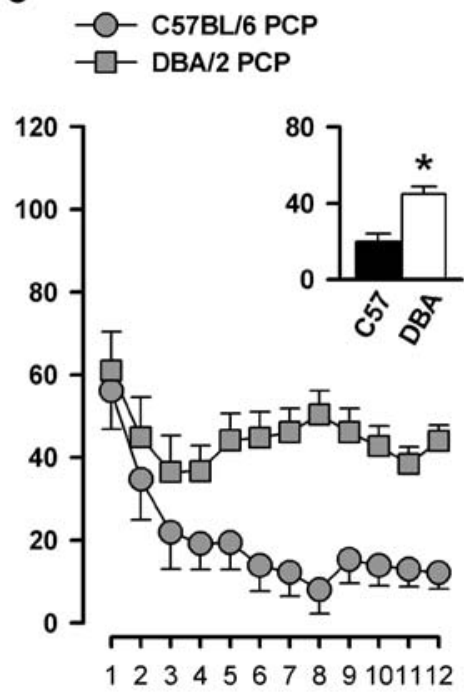

10-min bins

Fig. 5 Summary of the results of experiment 4. Distance travelled per 10-min bins following vehicle saline (a), amphetamine (b) and phencyclidine $(P C P)(\mathbf{c})$ is separately plotted to contrast the two mouse strains (C57 C57BL/6, DBA DBA/2). Insets in each graph represent the mean distance travelled per bin collapsed across bins to illustrate the relative augmentation of locomotor response in DBA/2

these presumed differences in neurotransmission function are causally related to the behavioural divergence observed. In addition to confirming earlier speculations on the behavioural and cognitive characteristics of DBA mice (e.g. Baarendse et al. 2008; Olivier et al. 2001), the present study also provides fresh insights that are highly relevant to the purported use of this strain comparison as a means to model selected schizophrenia traits in animals in terms of face, predictive (of drugs with antipsychotic potential) and construct (e.g. genetic, developmental and physiological differences) validity.

Deficient prepulse inhibition against a background of reduced startle reactivity in $\mathrm{DBA} / 2$ mice

We have first addressed the reliability of the reported relative PPI deficiency in DBA/2 mice because it is known that confounding change in startle reaction has been repeatedly noted in previous reports (e.g. Bortolato et al. 2007; Crawley et al. 1997; McCaughran et al. 1997; Paylor and Crawley 1997). Ignoring such confounding differences in startle reactivity can seriously undermine the validity of any claim as to whether PPI expression differs between groups (see Swerdlow et al. 2000). As can be readily seen in Figs. $2 \mathrm{a}$ and $3 \mathrm{~b}$, the absolute reduction in startle reactivity was heavily influenced by the corresponding baseline reactivity to the startle-eliciting pulse stimulus in C57BL/6 mice: This sensitivity to the prepulse stimulus 10-min bins mice (in a and c, as indicated by asterisk). All mean values are illustrated with the associated standard errors $( \pm \mathrm{SE})$ obtained from the overall three-way ANOVA conducted using SPSS for Windows (version 13), which are appropriate for comparisons between the illustrated mean values

was less pronounced when the startle reaction to the pulse stimulus was weaker. Hence, it is not inconceivable that the apparent deficiency in PPI observed in DBA/2 mice was related to their generally weaker startle reactivity. It therefore poses an important interpretative problem because this confound might lead to the identification of startlecorrective therapy rather than PPI-corrective treatment. To overcome this confounding effect, we adopted a recently developed PPI test paradigm incorporating multiple pulse stimulus intensities (Yee et al. 2005), which allowed the startle reaction between the two strains to be balanced or even reversed, thus providing an insight into a possible dependency on the existing strain difference in startle reactivity. The principle of its application is similar for both experiments 1 and 2, although the critical (crossed pulse intensity) comparisons being emphasised differed somewhat. The conclusions were identical: The relative PPI deficiency in DBA/2 mice cannot be solely attributed to their weaker startle response. The robustness and flexibility of this analytical approach in overcoming baseline startle reactivity difference in general was thus also demonstrated (Csomor et al. 2008; Yee et al. 2005). Based on this approach, we can also conclude that DBA/2 mice cannot be characterised as "low-startling" C57BL/6 mice in terms of the PPI expression. We have previously shown that when a random sample of $\mathrm{C} 57 \mathrm{BL} / 6$ mice were segregated into subgroups differing in startle reactivity, and the subgroups then compared, the apparent differences in PPI indexes 
calculated according to convention (\%PPI) would be eliminated when a crossed pulse intensity comparison was conducted to balance the reaction on pulse-alone conditions (Yee et al. 2005). This method of analysis thus showed that PPI expression was essentially comparable between C57BL/6 mice differing in startle magnitude. There is no reason to suspect that the same situation would not hold for other inbred mouse strains. Hence, the confirmation of the strain difference in PPI expression in the present study has clarified considerably the concern over the confounding difference in startle reactivity. We conclude that the regulation of PPI expression was different between these two mouse strains.

A schizophrenia-related trait in C57BL/6 in comparison to $\mathrm{DBA} / 2$ mice?

Experiment 1 showed clearly the absence of startle habituation in C57BL/6 mice against the clear presence of startle habituation in the DBA/2 mice (Fig. 2a). A consistent pattern of results was replicated in experiment 2 (Table 1). Indeed, the lack of startle habituation in $\mathrm{C} 57 \mathrm{BL} / 6$ mice is a robust result in agreement with earlier reports (Pietropaolo et al. 2008; Yee et al. 2004a, 2005). Given that impairment in startle reflex habituation is also present in schizophrenia patients and may be related to impaired selective attention (Geyer and Braff 1987; Geyer et al. 1990), should one also consider this strain-specific trait as a potential schizophrenia-related endophenotype? This certainly warrants further assessment, including the psychological nature of this phenotype as well as its relationship to PPI disruption in patients. Our data provide three relevant perspectives in this regard: (1) Clozapine was ineffective in promoting startle habituation in C57BL/6 mice (see Table 1), although the mice were responsive to the drug in terms of PPI expression (experiment 2). (2) The PPI deficiency demonstrated in $\mathrm{DBA} / 2$ mice relative to C57BL/6 mice was obviously not associated with an impairment in startle habituation (experiments 1 and 2). (3) The startle habituation deficit seen in C57BL/6 mice cannot be generalised to other responses because habituation of locomotor activity in the open field was equally observed in C57BL/6 and DBA/2 mice (Fig. 4a). Hence, it is unlikely that C57BL/6 mice suffer from a generalised weakening of habituation and/or strengthening of sensitisation processes.

It has not escaped our notice that the presence of startle habituation in DBA/2 but not $\mathrm{C} 57 \mathrm{BL} / 6$ mice might have contributed to the overall strain difference in startle reactivity seen across the test session (as recorded in the middle block of the test session used to assess PPI). We therefore explicitly compared all PPI-related measures by splitting the session into two halves and repeated all relevant analyses. This did not yield any deviation from our overall conclusion described above. Therefore, the difference in startle habituation does not undermine the confidence in our interpretations of the PPI data. Our results point to an intriguing double dissociation ${ }^{1}$ in this strain comparison, with deficiency in one form of startle plasticity found only in one mouse strain (PPI deficiency in DBA/2) and another form of anomaly only in the other strain (startle habituation deficit in C57BL/6). Interestingly, both phenotypes are of relevance to schizophrenia. This double dissociation in itself calls for caution in the use, or interpretation, of a given pairwise strain comparison as a general model of schizophrenia because either strain may be considered as more or less schizophrenia-like. The comparison should be made in a trait-by-trait, or endophenotype-by-endophenotype, manner (Arguello and Gogos 2006).

Responsiveness to systemic clozapine in PPI expression

Experiment 2 examined whether the baseline difference in PPI expression which emerged between DBA/2 and C57BL/6 mice would suggest that the former strain might therefore be more powerful in detecting the effect of atypical antipsychotic drugs, as exemplified by clozapine. If so, then one may conclude that the DBA/2 strain may represent a disease model such that its sensitivity to antipsychotic drugs signifies a correction or normalisation of PPI function, at least within the restrictive comparison to C57BL/6 mice. Thus, the answer to this question would bear significance for the increasingly widespread use of DBA/2 mice (often exclusively, without a comparison strain) as a model to detect the PPI-corrective property of novel antipsychotic drugs (e.g. Boulay et al. 2008; Depoortère et al. 2005; Fox et al. 2005; Kinney et al. 2003), as if another strain would yield a false negative outcome. The results of experiment 2 are clear: Against a demonstrated baseline (vehicle treatment) strain difference in PPI expression (Fig. 3e), clozapine was efficacious in significantly enhancing PPI in both mouse strains (Fig. 3d). These findings therefore do not support the suggestion that $\mathrm{DBA} / 2$ mice are superior (at least to $\mathrm{C} 57 \mathrm{BL} / 6$ mice) in detecting the effect of atypical antipsychotic drugs (clozapine here) on PPI. This conclusion is consistent with an earlier study by McCaughran et al. (1997) who showed that the C57BL/6 and DBA/2 were similarly effective in detecting the PPI-enhancing effect of clozapine as well as

\footnotetext{
${ }^{1}$ Strictly speaking, this is not a classical double dissociation due to a lack of a common control comparison group against which the DBA/2 and C57BL/6 strains can be compared. Here, DBA/2 mice showed a relative impairment in PPI, whilst C57BL/6 mice exhibited a lack of startle habituation when they were compared with each other.
} 
other atypical and typical antipsychotic drugs. However, a dose-response analysis would be necessary to consolidate such a claim by showing that when startle reactivity is balanced between strains, the dose-response curves of the two strains would overlap each other. Our present experiment had investigated a single dose of clozapine only, and the conclusion therefore needs to be restricted to that particular dose. Nonetheless, the responsiveness of C57BL/ 6 mice to this dose was clear and comparable to that seen in DBA/2 mice.

Again, the crossed pulse intensity analysis has been highly instrumental in allowing us to arrive at this critical conclusion amidst the confounding effects on startle reactivity (pulse-alone trials) of clozapine treatment as well as between mouse strains. It also suggests that at the highest pulse intensity of $120 \mathrm{~dB}$, clozapine merely produced an overall downward shift of startle reactivity in both mouse strains (Fig. 3a, b). In such case, expression of PPI as percent startle inhibition relative to pulse-alone reactivity would give an erroneous impression of PPI enhancement. This is most obviously seen in the report by Ouagazzal et al. (2001) who claimed that clozapine was effective in enhancing PPI, based on \%PPI analysis alone, at a dose of $30 \mathrm{mg} / \mathrm{kg}$ when startle response was massively reduced to less than one fifth of the control group level (i.e. a $82 \%$ reduction in startle reactivity) due presumably to the sedative effect of clozapine at such high doses. Our analysis overcame this problem and further indicated that the PPIenhancing effect of clozapine was more readily shown in both strains at lower pulse intensities $(100-110 \mathrm{~dB})$. This may suggest that if DBA/2 mice are more sensitive to this effect of clozapine (and by extension other atypical antipsychotic drugs), it is because they inherently exhibit lower startle reactivity. This, however, can be readily mimicked by the use of lower pulse intensity in C57BL/6 mice, and under such conditions, the PPI-enhancing effect of clozapine can also be readily detected. Hence, whilst we showed that the PPI deficiency of $\mathrm{DBA} / 2$ relative to C57BL/6 mice cannot be explained solely due to the confounding change in startle response (experiment 1), the reported impression that DBA/2 mice seem to be more suitable for the detection of atypical antipsychotic property in PPI may indeed stem from the reduced startle reaction native to this mouse strain. This highlights another important potential benefit of PPI tests that include multiple pulse stimulus intensities.

Another possibility is that $\mathrm{DBA} / 2$ mice were more responsive than $\mathrm{C} 57 \mathrm{BL} / 6$ to disruption by NMDA receptor antagonists and thereby more suitable or sensitive in detecting atypical antipsychotic drugs (Geyer 2006a, b). First of all, PPI expression in C57BL/6 is indeed sensitive to NMDA receptor antagonism (Yee et al. 2004a), so the comparison must be based on relative rather than absolute sensitivity. Using a dose-response analysis $(0,10,15$ or $20 \mathrm{mg} / \mathrm{kg}$ ), Spielewoy and Markou (2004) compared the sensitivity to PCP in four mouse strains (C57BL/6, DBA2, $\mathrm{C} 3 \mathrm{H} / \mathrm{He}$ and $129 \mathrm{~T} 2 / \mathrm{SvEms}$ ) and concluded that $\mathrm{C} 57 \mathrm{BL} / 6$ was the least sensitive, or even statistically insensitive. However, it seems that these authors have overinterpreted their own data since the conclusion was inconsistent across experiments (see their Figs. 1 and 3). Closer examination of their data also suggests that the dose-response relationship in C57BL/6 mice was somewhat shifted to the left of that of DBA/2 mice (see their Fig. 1a, b). Finally, their PPI evaluation failed to take into account the demonstrated strain-dependent effects of PCP treatment on startle reactivity that would certainly confound the interpretation of the data (see their Fig. 2). We therefore conclude that there is no convincing evidence to date to suggest that $\mathrm{DBA} / 2$ and $\mathrm{C} 57 \mathrm{BL} / 6$ mice differ substantially in their responsiveness to NMDA antagonists-induced PPI disruption. This issue should be addressed directly, but caution over confounding changes in startle reactivity must be exercised.

\section{Beyond PPI deficiency}

DBA/2 mice exhibited a parallel deficiency in the expression of LI under conditions in which $\mathrm{C} 57 \mathrm{BL} / 6$ mice showed robust LI (Experiment 3a, Fig. 4a), thereby extending the recent finding by Baarendse et al. (2008) who compared LI expression between DBA/2 and C57BL/ mice in a passive avoidance paradigm. Similar to PPI, LI is also impaired in at least a subset of schizophrenia patients (e.g. Baruch et al. 1988; Gray et al. 1992). Whilst PPI is suggested to measure the pre-attentive filtering or gating process (e.g. Ellenbroek 2004; Geyer 2006a), LI is more closely related to learned inattention, i.e. learning to ignore irrelevant stimuli in one's environment (e.g. Gray et al. 1991, 1995; Lubow 1989; Mackintosh 1973; Wagner 1978). The concomitant presence of PPI and LI deficiency (in DBA/2 mice relative to $\mathrm{C} 57 \mathrm{BL} / 6$ mice) demonstrated here in a within-subject manner lends further evidence that this strain comparison may capture more than one endophenotype related to schizophrenia.

The particular form of LI disruption in DBA/2 mice came about through a loss of the stimulus pre-exposure effect, i.e. CS pre-exposure failed to slow down subsequent learning about the predictive value of that stimulus, as well as through an impairing effect on learning in the nonpre-exposed condition-a novel finding that was most clearly shown in experiment 3B (Fig. 4c). It has been suggested that the latter effect might be interpreted as: (1) a general learning deficit-the DBA/2 mice learned less about the CS-US association, just as the DBA/2 PE mice had learned less about the CS-nothing association or the 
irrelevance of the CS during pre-exposure (see Yee et al. 1995), or (2) a failure to benefit from the context preexposure effect (i.e. latent inhibition to the context (e.g. Killcross et al. 1998), which should reduce the salience of the context and enhance attention to the CS (and thereby learning of its predictive significance) during subsequent conditioning for the NPE animals (see Pouzet et al. 2004). It should also be emphasised that the relative deficit in avoidance learning in DBA/2 mice was expressed against the background of enhanced spontaneous shuttle responses recorded in the ITIs, with $\mathrm{C} 57 \mathrm{BL} / 6$ mice exhibiting very low levels of spontaneous shuttles from the second block onwards. Hence, the poorer performance in $\mathrm{DBA} / 2$ mice cannot be explained by the relative difference in spontaneous shuttles. The higher spontaneous shuttle rate in DBA/2 mice would, if anything, allow some successful avoidance responses to be made by chance alone. The conclusion that $\mathrm{DBA} / 2$ mice are impaired in at least this form of associative learning is a novel observation that certainly warrants further evaluation. This is in direct conflict with two previous studies showing an opposite strain difference in a similar two-way active avoidance task (Bovet et al. 1969; Vetulani et al. 1989) when training was extended beyond the first hundred trials. Although we had only performed 100 trials here, it is unlikely that our observed pattern of results would reverse if additional training was conducted. A survey on the existing literature, however, does not seem to yield a clear consensus on this particular strain difference in avoidance learning, with some reports also failing to identify any clear performance difference (see Bovet et al. 1969; Iso and Shimai 1991; Sprott and Stavnes 1975; Stavnes and Sprott 1975b; Vetulani et al. 1989; Wahlsten 1972; Weinberger et al. 1992). A number of factors have been proposed to account for such apparent inconsistency, including shock intensity (Carran et al. 1964; Wahlsten 1972), the modality of the conditioned stimulus (Oliverio 1967), the training protocol (Wimer et al. 1968) and the age of the animals (Stavnes and Sprott 1975a). Another possibility is the precise source or stock of the mice obtained. Genetic drift away from the original Jackson stocks may occur to varying degrees depending on the breeding system maintained by the supplying laboratory. Unfortunately, no single factor can yet fully account for all reported results.

With respect to the precise pattern of LI abolition shown in experiment $3 \mathrm{~A}$, it closely resembles that seen following cell lesion of the entorhinal cortex (Yee et al. 1995, 1997), which abolishes LI via a disruption of the entorhinalstriatal projection, thereby disturbing the balance between glutamatergic and dopaminergic activities in the nucleus accumbens (Gray et al. 1995). On the other hand, it is distinctly different from the effect of cell lesions of the hippocampus, which lead to abnormally persistent LI
(Honey and Good 1993). It therefore contradicts the description of the $\mathrm{DBA} / 2$ strain (in comparison of the C57BL/6 strain) as a model or manifestation of a loss of hippocampal function, with relatively poor performance (compared with $\mathrm{C} 57 \mathrm{BL} / 6$ mice) in tasks requiring the formation of complex contextual representations including spatial learning as well as contextual fear conditioning (e.g. Ammassari-Teule et al. 2000a, 2000b, 1995; Barber et al. 1974; Gerlai 1998; Paylor et al. 1993, 1994; Wehner et al. 1990; Wimer et al. 1976).

The aberrant persistence of LI expression has been emphasised by Weiner (2003) as a model of negative and cognitive symptoms of schizophrenia. It can be induced in animals by NMDA receptor blockade or selective brain lesions to the nucleus accumbens core, basolateral amygdala or orbitofrontal cortex, and its normalisation has been specifically linked to atypical (but not typical) antipsychotic drugs (Gaisler-Salomon and Weiner 2003; GaislerSalomon et al. 2008; Lipina et al. 2005; Schiller et al. 2006). Experiment 3B examined this possibility by using a smaller number of stimulus pre-exposures, which was insufficient to generate LI in $\mathrm{C} 57 \mathrm{BL} / 6$ mice (and the sensitivity of this procedure to the induction of abnormally persistent LI by NMDA receptor blockade has been confirmed in our laboratory; W-N. Zhang, P. Singer, J. Feldon, and B.K. Yee, unpublished data). Against this background, LI was similarly absent in the DBA/2 mice, which also exhibited again an overall deficit in avoidance learning. Extension of this null finding to other procedural manipulations designed to minimise LI expression in the reference control group (e.g. increased number of CS-US pairings or contextual change between pre-exposure and conditioning) would be highly relevant. One previous study has reported that $16 \mathrm{CS}$ pre-exposures (distributed across 4 days) followed by two CS-US pairings in a conditioned freezing paradigm led to $\mathrm{LI}$ in $\mathrm{DBA} / 2$ but not C57BL/6 mice (Restivo et al. 2002), but the statistical evidence provided was weak, and careful examination revealed that their test condition was far from ideal-with a trend of LI effect obtained in C57BL/6 mice, reportedly at $p=0.06$.

According to the "two-headed" latent inhibition model of schizophrenia formulated by Weiner (2003), our LI experiments with DBA/2 mice would suggest an interpretation of this mouse strain in terms of positive symptoms rather than negative/cognitive symptoms of schizophrenia. The latter in particular would disagree with the suggestion that the PPI relative deficiency demonstrated in experiments 1 and 2 would be predictive of cognitive symptoms in schizophrenia (Geyer 2006a). As discussed below, the outcomes of the psychostimulant drugs experiment have yielded some support to both perspectives in terms of neuropharmacology. 
Altered locomotor response to dopamine receptor agonism and NMDA receptor antagonism in DBA/2 mice

One physiological perspective on the distinction between positive and negative/cognitive symptoms of schizophrenia emphasises the respective contributions of dopaminergic hyperfunction and glutamatergic/NMDA receptor hypofunction. As mentioned above, these two hypothesised pathophysiological mechanisms are both highly relevant to the interpretation and application of the PPI and LI models of the relevant psychopathology. The LI phenotypes of $\mathrm{DBA} / 2$ mice here are suggestive of dopaminergic dysfunction (Weiner 2003), whereas the PPI deficiency and its responsiveness to clozapine may be indicative of glutamatergic/NMDA receptor hypofunction (Geyer 2006a, b). These suggestions were therefore examined by acute systemic challenge of a dopamine-releasing drug (amphetamine) or an NMDA receptor blocker (PCP) in these animals (experiment 4).

First of all, a clear baseline difference was observed with DBA/2 mice showing a higher level of activity (Fig. 5a), which was also seen on the pre-exposure day of the LI experiments with a different activity measure, namely total number of spontaneous shuttles (experiments $3 \mathrm{~A}$ and $3 \mathrm{~B}$ ). We have since also replicated this finding in a separate cohort of naïve $\mathrm{DBA} / 2$ and $\mathrm{C} 57 \mathrm{BL} / 6$ mice, and thus, prior test experience here does not seem to account for the present outcome (P. Singer, J. Feldon and B.K. Yee, unpublished observation). This impression is in keeping with some (Morse et al. 1993; Tohmi et al. 2005) but not other reports that have either shown an opposite pattern of results (e.g. Cabib et al. 2000, 2002; McNamara et al. 2006) or failed to reveal any difference between these two mouse strains (Cabib et al. 2000; Ventura et al. 2004). Such inconsistency may stem from the critical importance of environmental factors including housing conditions (Morse et al. 1993), feeding regime (Cabib and Bonaventura 1997) and light/dark phase of the diurnal cycle (P. Singer, J. Feldon and B.K. Yee, unpublished observation). Such environmental factors in conjunction with the reported enhanced sensitivity to stress in DBA/2 mice in comparison to C57BL/6 mice (see e.g. Badiani et al. 1992; Cabib et al. 2000) may also contribute to the observed results in the drug phase of the experiment here.

Although the baseline (vehicle treatment) difference between strains renders interpretation of the overall magnitude of drug-induced locomotor response somewhat difficult, the temporal profile of the response clearly differed between the two mouse strains. The onset and offset of the peak response to amphetamine were accelerated in DBA/2 mice by $10-20$ min relative to $\mathrm{C} 56 \mathrm{BL} / 6$ mice (Fig. 5b), with little change in the overall absolute activity levels. This outcome is in conflict with previous studies reporting a relative reduction of motor response in $\mathrm{DBA} / 2$ mice that has been linked to an increase in amphetamine-induced dopamine release in the prefrontal cortex, which in turn suppresses dopamine release in the nucleus accumbens that mediates the hyperactivity effect (Ventura et al. 2004; Zocchi et al. 1998). However, when the baseline difference in activity level observed here is taken into account, the motor stimulant effect of amphetamine might, on the contrary, be considered weaker in the DBA/2 mice relative to the $\mathrm{C} 57 \mathrm{BL} / 6$ mice and would not be in direct disagreement with the reports by Ventura et al. (2004) and Zocchi et al. (1998). Nonetheless, the more rapid onset of hyperlocomotor response to amphetamine in the DBA/2 mice here might be expected on the basis of known dopaminergic differences between DBA/2 and C57BL/6 mice. Firstly, a relative reduction in $\mathrm{D}_{2}$-like dopamine receptors density in the nucleus accumbens (Puglisi-Allegra and Cabib 1997) might allow a higher proportion of the receptors to be activated more quickly in DBA/2 mice. Secondly, enhanced dopamine release in the medial prefrontal cortex (Ventura et al. 2004) and a higher number of $\mathrm{D}_{2}$-like receptors in the ventral tegmental area and substantia nigra, in combination with a higher dopaminergic autoreceptors-to-postsynaptic receptors ratio in the striatum (Puglisi-Allegra and Cabib 1997), might all contribute to facilitate the inhibition of mesolimbic dopaminergic hyperactivity induced by amphetamine (Zocchi et al. 1998).

In response to PCP, both mouse strains showed an increase in activity to a similar absolute magnitude within the first bin (Fig. 5c), which is in contrast to the initial impact of amphetamine challenge such that the baseline strain difference persisted in the first two bins post-injection (Fig. 5b). Subsequently, the activity level in the PCP-treated C57BL/6 mice gradually returned to that of vehicle-treated $\mathrm{C} 57 \mathrm{BL} / 6$ mice. In contrast, the cessation of the motor response to $\mathrm{PCP}$ challenge was less rapid in the DBA/2 mice and still had not returned to control levels by the session's end. Hence, even if one argues that their initial response was weaker than $\mathrm{C} 57 \mathrm{BL} / 6$ mice in terms of proportional elevation of activity level relative to vehicle treatment, the interpretation that their response was protracted in time remains non-negotiable. One way to overcome the confounding difference in baseline activity difference (pre-drug phase in a within-subject design or vehicle treatment as in a between-subject design adopted here) is to use a subtraction scoring method. Based on this, Alexander et al. (1996) concluded that DBA/2 and C57BL/ 6 mice do not differ in their overall response to PCP, although they did not provide a temporal profile analysis. Given that current data on this issue are scant, further investigations are certainly warranted. 
The absence of concurrent neurochemical measures in the present study, however, precludes an extended discussion of the possible differences in neurotransmitter functions between DBA/ 2 and C57BL/ 6 mice. Nonetheless, the evidence here is suggestive of differences between these two mouse strains in both dopaminergic and glutamatergic functions, including perhaps their interaction. It remains to be determined whether these neuropharmacological differences may underlie some of the key behavioural and cognitive divergence between them.

\section{A postscript on the caveats in strain comparison studies}

Whilst strain comparison between inbred strains of laboratory rodents can be a fruitful approach in behavioural genetics, the present study also illustrates that care and caution must be exercised in the interpretation of the data because it is often the case that different strains are associated with multiple behavioural differences. These can be significant confounding variables in one particular experiment, yet not in another. The present study was motivated first and foremost by the need to address the significant confounding changes in startle reactivity and their possible impact on interpreting PPI data. This was explicitly addressed here for the first time and was resolved using a novel paradigm designed particularly for dealing with such a confound. In addition, critical confounding changes were also recognised in all subsequent tests conducted. In the assessment of LI, the results were confounded by strain difference in avoidance learning as such, which in turn was confounded by differences in the frequency of spontaneous shuttle responses. In both experiments (experiments 3A and 3B), appreciation of these confounds have enriched rather than limited our interpretation of the data. In evaluating the motor stimulating effect of psychomimetic drugs, interpretation of the data derived from the drugged groups was confounded by baseline strain difference in the vehicle treatment condition. This, however, cannot be easily overcome, except by the use of a within-subject design in combination with prolonged apparatus habituation to minimise or eliminate such baseline differences.

\section{Conclusion}

There is a strong genetic component to schizophrenia, and therefore, comparative studies of inbred laboratory rodents offer an opportunity to identify the genetic and associated physiological mechanisms that may underlie selected endophenotypes of the disease. The comparison between DBA/2 and C57BL/6 mice may represent a promising comparative couple perhaps in the search of potential candidate genes, neural mechanisms and neurodevelopmental divergences that may underlie the pathophysiology of multiple schizophrenia-related endophenotypes. It is a welcomed addition to the bottom-up approach of point mutation generated by genetic engineering. However, unlike treatment-based disease models, such as mutations, drugs or specific neurodevelopmental interference, the precise cause and effect relationship underlying strain differences is particularly difficult to pin down because the mouse strains are "given to" rather than "by design of" the experimenter. To harness the power of such mouse strain models, testable hypotheses targeting individual phenotypic components ought to be thoroughly evaluated by other experimental approaches.

Lastly, it is essential to recognise that comparative analysis of behavioural phenotypes between strains is necessarily relative in nature and is heavily influenced by the choice of the control or reference strain. The behavioural deficiencies in the DBA/2 mice revealed here are all based on a unique comparison with the $\mathrm{C} 57 \mathrm{BL} / 6$ strain, and it is not at all difficult to conceive that a very different picture may emerge if another reference strain were employed. It would be inappropriate to refer to the $\mathrm{DBA} / 2$ mouse strain as a "psychotic" mouse strain in absolute terms. In contrast, schizophrenia is recognised as a disease entity in the clinic, and the diagnostic criteria are designed to minimise such arbitrary relativism. Relatively speaking, the DBA/2 strain may be associated with a propensity to develop behavioural traits that may resemble those of schizophrenia, but this does not imply that these mice are suffering from psychosis.

Acknowledgments The present study was supported by the Federal Institute of Technology Zurich and the National Centre of Competence in Research (NCCR): Neural Plasticity and Repair funded by the Swiss National Science Foundation.

\section{References}

Alexander RC, Wright R, Freed W (1996) Quantitative trait loci contributing to phencyclidine-induced and amphetamine-induced locomotor behavior in inbred mice. Neuropsychopharmacology 15:484-490

Ammassari-Teule M, Passino E, Restivo L, de Marsanich B (2000a) Fear conditioning in $\mathrm{C} 57 \mathrm{BL} / 6$ and $\mathrm{DBA} / 2$ : variability in nucleus accumbens according to the strain predisposition to show contextual- or cue-based responding. Eur J Neurosci 12:44674474

Ammassari-Teule M, Restivo L, Passino E (2000b) Contextualdependent effects of nucleus accumbens lesions on spatial learning in mice. Neuroreport 11:2485-2490

Ammassari-Teule M, Tozzi A, Rossi-Arnaud C, Save E, Thinus-Blanc C (1995) Reactions to spatial and nonspatial change in two inbred strains of mice: further evidence supporting the hippo- 
campal dysfunction hypothesis in the DBA/2 strain. Psychobiology 23:284-289

Arguello PA, Gogos JA (2006) Modeling madness in mice: one piece at a time. Neuron 52:179-196

Badiani A, Cabib S, Puglisi-Allegra S (1992) Chronic stress induces strain-dependent sensitization to the behavioral effects of amphetamine in the mouse. Pharmacol Biochem Behav 43:53-60

Baarendse PJ, van Grootheest G, Jansen RF, Pieneman AW, Ogren SO, Verhage M, Stiedl O (2008) Differential involvement of the dorsal hippocampus in passive avoidance in $\mathrm{C} 57 \mathrm{bl} / 6 \mathrm{~J}$ and DBA/ 2J mice. Hippocampus 18:11-19

Barber RP, Vaughn JE, Wimer RE, Wimer CC (1974) Geneticallyassociated variations in the distribution of dentate granule cells synapses upon the pyramidal cell dendrites in the mouse hippocampus. J Comp Neurol 156:417-434

Baruch I, Hemsley D, Gray JA (1988) Differential performance of acute and chronic schizophrenic in a latent inhibition task. J Nerv Ment Dis 176:598-606

Bortolato M, Frau R, Orrù M, Piras AP, Fà M, Tuveri A, Puligheddu M, Gessa GL, Castelli MP, Mereu G, Marrosu F (2007) Activation of GABA(B) receptors reverses spontaneous gating deficits in juvenile DBA/2J mice. Psychopharmacology 194:361369

Boulay D, Pichat P, Dargazanli G, Estenne-Bouhtou G, Terranova JP, Rogacki N, Stemmelin J, Coste A, Lanneau C, Desvignes C, Cohen C, Alonso R, Vigé X, Biton B, Steinberg R, Sevrin M, Oury-Donat F, George P, Bergis O, Griebel G, Avenet P, Scatton B (2008) Characterization of SSR103800, a selective inhibitor of the glycine transporter-1 in models predictive of therapeutic activity in schizophrenia. Pharmacol Biochem Behav 91:47-58

Bovet D, Bovet-Nitti F, Oliverio A (1969) Genetic aspects of learning and memory in mice. Science 163:139-149

Braff DL, Geyer MA, Swerdlow NR (2001) Human studies of prepulse inhibition of startle: normal subjects, patient groups, and pharmacological studies. Psychopharmacology (Berl) 156:234-258

Braff DL, Grillon C, Geyer MA (1992) Gating and habituation of the startle reflex in schizophrenic patients. Arch Gen Psychiatry 49:206-215

Browman KE, Komater VA, Curzon P, Rueter LE, Hancock AA, Decker MW, Fox GB (2004) Enhancement of prepulse inhibition of startle in mice by the $\mathrm{H} 3$ receptor antagonists thioperamide and ciproxifan. Behav Brain Res 153:69-76

Bullock AE, Slobe BS, Vazques V, Collins AC (1997) Inbred mouse strains differ in the regulation of startle and prepulse inhibition of the startle response. Behav Neurosci 111:1353-1360

Cabib S, Bonaventura N (1997) Parallel strain-dependent susceptibility to environmentally-induced stereotypies and stress-induced behavioral sensitization in mice. Physiol Behav 61:499-506

Cabib S, Orsini C, Le Moal M, Piazza PV (2000) Abolition and reversal of strain differences in behavioral responses to drugs of abuse after a brief experience. Science 289:463-465

Coyle JT (2006) Glutamate and schizophrenia: beyond the dopamine hypothesis. Cell Mol Neurobiol 26:365-384

Cabib S, Puglisi-Allegra S, Ventura R (2002) The contribution of comparative studies in inbred strains of mice to the understanding of the hyperactive phenotype. Behav Brain Res 130:103109

Carlsson A (1988) The current status of the dopamine hypothesis of schizophrenia. Neuropsychopharmacology 1:179-186

Carran AB, Yeudall LT, Royce JR (1964) Voltage level and skin resistance in avoidance conditioning in inbred strains of mice. J Comp Physiol Psychol 58:427-430

Chang T, Meyer U, Feldon J, Yee BK (2007) Disruption of the US pre-exposure effect and latent inhibition in two-way active avoidance by systemic amphetamine in C57BL/6 mice. Psychopharmacology (Berl) 191:211-221
Crawley JN, Belknap JK, Collins A, Crabbe JC, Frankel W, Henderson N, Hitzemann RJ, Maxson SC, Miner LL, Silva AJ, Wehner JM, Wynshaw-Boris A, Paylor R (1997) Behavioral phenotypes of inbred mouse strains: implications and recommendations for molecular studies. Psychopharmacology (Berl) 132:107-124

Csomor PA, Yee BK, Quednow BB, Stadler RR, Feldon J, Vollenweider FX (2006) The monotonic dependency of prepulse inhibition of the acoustic startle reflex on the intensity of the startle-eliciting stimulus. Behav Brain Res 174:143-150

Csomor PA, Yee BK, Feldon J, Theodoridou A, Studerus E, Vollenweider FX (2009) Impaired prepulse inhibition and prepulse-elicited reactivity but intact reflex circuit excitability in unmedicated schizophrenia patients: a comparison with healthy subjects and medicated schizophrenia patients. Schizophr Bull 35:244-255

Csomor PA, Yee BK, Vollenweider FX, Feldon J, Nicolet T, Quednow BB (2008) On the influence of baseline startle reactivity on the indexation of prepulse inhibition. Behav Neurosci 122:885-900

Depoortère R, Dargazanli G, Estenne-Bouhtou G, Coste A, Lanneau C, Desvignes C, Poncelet M, Heaulme M, Santucci V, Decobert M, Cudennec A, Voltz C, Boulay D, Terranova JP, Stemmelin J, Roger P, Marabout B, Sevrin M, Vigé X, Biton B, Steinberg R, Françon D, Alonso R, Avenet P, Oury-Donat F, Perrault G, Griebel G, George P, Soubrié P, Scatton B (2005) Neurochemical, electrophysiological and pharmacological profiles of the selective inhibitor of the glycine transporter-1 SSR504734, a potential new type of antipsychotic. Neuropsychopharmacology 30:1963-1985

Ellenbroek BA (2004) Pre-attentive processing and schizophrenia: animal studies. Psychopharmacology (Berl) 174:65-74

Fox GB, Esbenshade TA, Pan JB, Radek RJ, Krueger KM, Yao BB, Browman KE, Buckley MJ, Ballard ME, Komater VA, Miner H, Zhang M, Faghih R, Rueter LE, Bitner RS, Drescher KU, Wetter J, Marsh K, Lemaire M, Porsolt RD, Bennani YL, Sullivan JP, Cowart MD, Decker MW, Hancock AA (2005) Pharmacological properties of ABT-239 [4-(2-\{2-[(2R)-2-methylpyrrolidinyl]ethyl\}-benzofuran-5-yl) benzonitrile]: II. Neurophysiological characterization and broad preclinical efficacy in cognition and schizophrenia of a potent and selective histamine $\mathrm{H} 3$ receptor antagonist. J Pharmacol Exp Ther 313:176-190

Gaisler-Salomon I, Weiner I (2003) Systemic administration of MK801 produces an abnormally persistent latent inhibition which is reversed by clozapine but not haloperidol. Psychopharmacology (Berl) 166:333-342

Gaisler-Salomon I, Diamant L, Rubin C, Weiner I (2008) Abnormally persistent latent inhibition induced by MK801 is reversed by risperidone and by positive modulators of NMDA receptor function: differential efficacy depending on the stage of the task at which they are administered. Psychopharmacology (Berl) 196:255-267

Gerlai R (1998) Contextual learning and cue association in fear conditioning in mice: a strain comparison and lesion study. Behav Brain Res 133:925-940

Geyer MA (2006a) The family of sensorimotor gating disorders: comorbidities or diagnostic overlaps? Neurotox Res 10:211-220

Geyer MA (2006b) Are cross-species measures of sensorimotor gating useful for the discovery of procognitive cotreatments for schizophrenia? Dialogues Clin Neurosci 8:9-16

Geyer MA, Braff DL (1987) Startle habituation and sensorimotor gating in schizophrenia and related animal models. Schizophr Bull 13:643-668

Geyer MA, McIlwain KL, Paylor R (2002) Mouse genetic models for prepulse inhibition: an early review. Mol Psychiatry 7:1039-1053

Geyer MA, Swerdlow NR, Mansbach RS, Braff DL (1990) Startle response models of sensorimotor gating and habituation deficits in schizophrenia. Brain Res Bull 25:485-498 
Gould TJ, Wehner JM (1999) Genetic influences on latent inhibition. Behav Neurosci 113:1291-1296

Gray JA, Feldon J, Rawlins JNP, Hemsley DR, Smith AD (1991) The neuropsychology of schizophrenia. Behav Brain Res 14:1-84

Gray NS, Hemsley DR, Gray JA (1992) Abolition of latent inhibition in acute, but not chronic schizophrenics. Neurol Psychiatry Brain Res 1:83-89

Gray JA, Joseph MH, Hemsley DR, Young AM, Warburton EC, Boulenguez P, Grigoryan GA, Peters SL, Rawlins JN, Taib CT (1995) The role of mesolimbic dopaminergic and retrohippocampal afferents to the nucleus accumbens in latent inhibition: implications for schizophrenia Behav Brain Res 71:19-31

Hince DA, Martin-Iverson MT (2005) Differences in prepulse inhibition (PPI) between Wistar and Sprague-Dawley rats clarified by a new method of PPI standardization. Behav Neurosci 119:66-77

Hoffman HS, Searle JL (1965) Acoustic variables in the modification of startle reaction in the rat. J Comp Physiol Psychol 60:53-58

Honey RC, Good M (1993) Selective hippocampal lesions abolish the contextual specificity of latent inhibition and conditioning. Behav Neurosci 107:23-33

Iso H, Shimai S (1991) Running-wheel avoidance learning in mice (Mus musculus): evidence of contingency learning and differences among inbred strains. J Comp Psychol 105:190-202

Javitt DC (2007) Glutamate and schizophrenia: phencyclidine, $N$ methyl- $d$-aspartate receptors, and dopamine-glutamate interactions. Int Rev Neurobiol 78:69-108

Killcross AS, Kiernan MJ, Dwyer D, Westbrook RF (1998) Loss of latent inhibition of contextual conditioning following nonreinforced context exposure in rats. Q J Exp Psychol B 51:75-90

Kinney GG, Sur C, Burno M, Mallorga PJ, Williams JB, Figueroa DJ, Wittmann M, Lemaire W, Conn PJ (2003) The glycine transporter type 1 inhibitor $N$-[3-(4'-fluorophenyl)-3-(4'-phenylphenoxy) propyl] sarcosine potentiates NMDA receptor-mediated responses in vivo and produces an antipsychotic profile in rodent behavior. J Neurosci 23:7586-7591

Lipina T, Labrie V, Weiner I, Roder J (2005) Modulators of the glycine site on NMDA receptors, D-serine and ALX 5407, display similar beneficial effects to clozapine in mouse models of schizophrenia. Psychopharmacology (Berl) 179:54-67

Logue SF, Owen EH, Rasmussen DL, Wehner JM (1997) Assessment of locomotor activity, acoustic and tactile startle, and prepulse inhibition of startle in inbred mouse strains and F1 hybrids: implications of genetic background for single gene and quantitative trait loci analyses. Neuroscience 80:1075-1086

Lubow RE (1989) Latent inhibition and conditioned attention theory. Cambridge University Press, New York

Lubow RE, Moore AU (1959) Latent inhibition: the effect of nonreinforced preexposure to the conditional stimulus. J Comp Physiol Psychol 66:688-694

Mackintosh NJ (1973) Stimulus selection: learning to ignore stimuli that predict no change in reinforcement. In: Hinde RA, Stevenson-Hinde J (eds) Constraints on learning. Academic, London, pp 75-96

McCaughran JJ, Mahjubi E, Decena E, Hitzemann R (1997) Genetics, haloperidol-induced catalepsy and haloperidol-induced changes in acoustic startle and prepulse inhibition. Psychopharmacology 134:131-139

McNamara RK, Levant B, Taylor B, Ahlbrand R, Liu Y, Sullivan JR, Stanford K, Richtand NM (2006) C57BL/6J mice exhibit reduced dopamine D3 receptor-mediated locomotor-inhibitory function relative to DBA/2J mice. Neuroscience 143:141-153

Morse AC, Erwin VG, Jones BC (1993) Strain and housing affect cocaine self-selection and open-field locomotor activity in mice. Pharmacol Biochem Behav 45:905-912
Olivier B, Leahy C, Mullen T, Paylor R, Groppi VE, Sarnyai Z, Brunner D (2001) The DBA/2J strain and prepulse inhibition of startle: a model system to test antipsychotics. Psychopharmacology (Berl) 156:284-290

Paylor R, Baskall L, Wehner JM (1993) Behavioral dissociations between C57BL/6 and DBA/2 mice on learning and memory tasks: a hippocampal dysfunction hypothesis. Psychobiology $21: 11-26$

Paylor R, Crawley JN (1997) Inbred strain differences in prepulse inhibition of the mouse startle response. Psychopharmacology 132:169-118

Paylor R, Tracy R, Wehner J, Rudy JR (1994) DBA/2 and C57BL/6 mice differ in contextual fear conditioning but not auditory fear conditioning. Behav Neurosci 108:810-817

Pietropaolo S, Singer P, Feldon J, Yee BK (2008) The postweaning social isolation in C57BL/6 mice: preferential vulnerability in the male sex. Psychopharmacology 197:613-628

Pouzet B, Zhang WN, Weiner I, Feldon J, Yee BK (2004) Latent inhibition is spared by $N$-methyl-D-aspartate (NMDA)-induced ventral hippocampal lesions, but is attenuated following local activation of the ventral hippocampus by intracerebral NMDA infusion. Neuroscience 124:183-194

Puglisi-Allegra S, Cabib S (1997) Psychopharmacology of dopamine: the contribution of comparative studies in inbred strains of mice. Prog Neurobiol 51:637-661

Oliverio A (1967) Effects of different conditioning schedules based on visual and acoustic conditioned stimulus on avoidance learning of two strains of mice. J Psychol 65:131-139

Ouagazzal AM, Jenck F, Moreau JL (2001) Drug-induced potentiation of prepulse inhibition of acoustic startle reflex in mice: a model for detecting antipsychotic activity? Psychopharmacology (Berl) 156:273-283

Restivo L, Passino E, Middei S, Ammassari-Teule M (2002) The strain-specific involvement of nucleus accumbens in latent inhibition might depend on differences in processing configuraland cue-based information between C57BL/6 and DBA mice. Brain Res Bull 57:35-39

Sandner G, Canal NM (2007) Relationship between PPI and baseline startle response. Cogn Neurodyn 1:27-37

Schmajuk NA, Larrauri JA (2005) Neural network model of prepulse inhibition. Behav Neurosci 119:1546-1562

Schmajuk NA, Gray JA, Lam YW (1996) Latent inhibition: a neural network approach. J Exp Psychol Anim Behav Process 22:321349

Schiller D, Zuckerman L, Weiner I (2006) Abnormally persistent latent inhibition induced by lesions to the nucleus accumbens core, basolateral amygdala and orbitofrontal cortex is reversed by clozapine but not by haloperidol. J Psychiatr Res 40:167-177

Schwabe K, Freudenberg F, Koch M (2007) Selective breeding of reduced sensorimotor gating in Wistar rats. Behav Genet 37:706-712

Snyder SH (1976) The dopamine hypothesis of schizophrenia: focus on the dopamine receptor. Am J Psychiatry 133:197-202

Spielewoy C, Markou A (2004) Strain-specificity in nicotine attenuation of phencyclidine-induced disruption of prepulse inhibition in mice: relevance to smoking in schizophrenia patients. Behav Genet 34:343-354

Sprott RL, Stavnes K (1975) Effects of situational variables on performance of inbred mice in active- and passive-avoidance situations. Psychol Rep 37:683-692

Stavnes K, Sprott RL (1975a) Effects of age and genotype on acquisition of an active avoidance response in mice. Dev Psychobiol 8:437-445

Stavnes KL, Sprott RL (1975b) Genetic analysis of active avoidance performance in mice. Psychol Rep 36:515-521

Stevens KE, Freedman R, Collins AC, Hall M, Leonard S, Marks MJ, Rose GM (1996) Genetic correlation of inhibitory gating of 
hippocampal auditory evoked response and alpha-bungarotoxinbinding nicotinic cholinergic receptors in inbred mouse strains. Neuropsychopharmacology 15:152-162

Stevens KE, Wear KD (1997) Normalizing effects of nicotine and a novel nicotinic agonist on hippocampal auditory gating in two animal models. Pharmacol Biochem Behav 57:869-874

Swerdlow NR, Braff DL, Geyer MA (2000) Animal models of deficient sensorimotor gating: what we know, what we think we know, and what we hope to know soon. Behav Pharmacol 11:185-204

Swerdlow NR, Geyer MA (1998) Using an animal model of deficient sensorimotor gating to study the pathophysiology and new treatments of schizophrenia. Schizophr Bull 24:285-301

Swerdlow NR, Weber M, Qu Y, Light GA, Braff DL (2008) Realistic expectations of prepulse inhibition in translational models for schizophrenia research. Psychopharmacology (Berl) 199:331388

Tohmi M, Tsuda N, Mizuno M, Takei N, Frankland PW, Nawa H (2005) Distinct influences of neonatal epidermal growth factor challenge on adult neurobehavioral traits in four mouse strains. Behav Genet 35:615-629

Ventura R, Alcaro A, Cabib S, Conversi D, Mandolesi L, PuglisiAllegra S (2004) Dopamine in the medial prefrontal cortex controls genotype-dependent effects of amphetamine on mesoaccumbens dopamine release and locomotion. Neuropsychopharmacology 29:72-80

Vetulani J, Battaglia M, Sansone M (1989) Nimodipine on shuttle-box avoidance learning in mice: no impairment but slight improvement. Pharmacol Biochem Behav 56:577-581

Wagner AR (1978) Expectancies and the priming of STM. In: Tighe TJ, Fowler H, Honig WK (eds) Cognitive processes in animal behavior. Erlbaum, Hillsdale, NJ, pp 177-209

Wahlsten D (1972) Phenotypic and genetic relations between initial response to electric shock and rate of avoidance learning in mice. Behav Genet 2:211-240

Wehner JM, Sleight S, Upchurch M (1990) Hippocampal protein kinase $\mathrm{C}$ is reduced in poor spatial learners. Brain Res 523:181-187

Weinberger SB, Koob GF, Martinez JL Jr (1992) Differences in oneway active avoidance learning in mice of three inbred strains. Behav Genet 22:177-188

Weiner I (2003) The "two-headed" latent inhibition model of schizophrenia: modelling positive and negative symptoms and their treatment. Psychopharmacology (Berl) 169:257-297
Williams JH, Wellman NA, Geaney DP, Cowen PJ, Feldon J, Rawlins JNP (1998) Reduced latent inhibition in people with schizophrenia: an effect of psychosis or of its treatment. Br J Psychiatry 172:243-249

Wimer RE, Symington L, Farmer H, Schwartzkroin P (1968) Differences in memory processes between inbred mouse strains C57BL/6J and DBA/2J. J Comp Physiol Psychol 65:126-131

Wimer RE, Wimer CC, Vaugh JE, Barber RP, Balvanz BA, Chernow CR (1976) The genetic organization of neuron number in Ammon's horns of house mouse. Brain Res 118:219-243

Yee BK, Feldon J (2009) Distinct forms of prepulse inhibition disruption distinguishable by the associated changes in prepulse-elicited reaction. Behav Brain Res (in press)

Yee BK, Balic E, Singer P, Schwerdel C, Grampp T, Gabernet L, Knuesel I, Benke D, Feldon J, Mohler H, Boison D (2006) Disruption of glycine transporter 1 restricted to forebrain neurons is associated with a procognitive and antipsychotic phenotypic profile. J Neurosci 26:3169-3181

Yee BK, Chang DL, Feldon J (2004a) The effects of dizocilpine and phencyclidine on prepulse inhibition of the acoustic startle reflex and on prepulse-elicited reactivity in C57BL6 mice. Neuropsychopharmacology 29:1865-1877

Yee BK, Chang T, Pietropaolo P, Feldon J (2005) The expression of prepulse inhibition of the acoustic startle reflex as a function of three pulse stimulus intensities, three prepulse stimulus intensities, and three levels of startle responsiveness in C57BL6/J mice. Behav Brain Res 163:265-276

Yee BK, Feldon J, Rawlins JN (1995) Latent inhibition in rats is abolished by NMDA-induced neuronal loss in the retrohippocampal region, but this lesion effect can be prevented by systemic haloperidol treatment. Behav Neurosci 109:227-240

Yee BK, Feldon J, Rawlins JN (1997) Cytotoxic lesions of the retrohippocampal region attenuate latent inhibition but spare the partial reinforcement extinction effect. Exp Brain Res 115:247256

Yee BK, Russig H, Feldon J (2004b) Apomorphine-induced prepulse inhibition disruption is associated with a paradoxical enhancement of prepulse stimulus reactivity. Neuropsychopharmacology 29:240-248

Zocchi A, Orsini C, Cabib S, Puglisi-Allegra S (1998) Parallel straindependent effect of amphetamine on locomotor activity and dopamine release in the nucleus accumbens: an in vivo study in mice. Neuroscience 82:521-528 